\title{
Intelligent Model Building and GPC-PID Based Temperature Curve Control Strategy for Metallurgical Industry
}

\author{
Shuanghong Li, ${ }^{1} \mathrm{Xi} \mathrm{Li}^{2}{ }^{2}$ and Yupu Yang ${ }^{1}$ \\ ${ }^{1}$ Department of Automation, Shanghai Jiao Tong University, 800 Dong Chuan Road, Shanghai 200240, China \\ ${ }^{2}$ School of Automation, Huazhong University of Science and Technology, 1024 Luo Yu Road, Wuhan 430074, China \\ Correspondence should be addressed to Shuanghong Li; lishuanghong1989@163.com
}

Received 26 November 2015; Accepted 9 February 2016

Academic Editor: Hiroyuki Mino

Copyright (c) 2016 Shuanghong Li et al. This is an open access article distributed under the Creative Commons Attribution License, which permits unrestricted use, distribution, and reproduction in any medium, provided the original work is properly cited.

\begin{abstract}
Laminar cooling process is a large-scale, nonlinear system, so the temperature control of such system is a difficult and complex problem. In this paper, a novel modeling method and a GPC-PID based control strategy for laminar cooling process are proposed to control the global temperature curve to produce high quality steel. First, based on the analysis of the cooling process of laminar flow, a new TS fuzzy model which possesses intelligence and self-learning ability is established to improve the temperature prediction accuracy. Second, the target temperature curve can be divided into several subgoals and each subgoal can be described by a CARIMA type of model. Then, by the decentralized predictive control method, GPC-PID based control strategy is introduced to guarantee the laminar cooling process to achieve subtargets, respectively; in that way the steel plate temperature will drop along the optimal temperature curve. Moreover, by employing the dSPACE control board into the process control system, the matrix process ability is added to the production line without large-scale reconstruction. Finally, the effectiveness and performance of the proposed modeling and control strategy are demonstrated by the industrial data and metallography detection in one steel company.
\end{abstract}

\section{Introduction}

Nowadays, higher requirements have been posed for the property of steel plates in fields like shipbuilding, auto industry, bridge construction, and so forth. The property of steel plates and their microstructures are, to a large extent, determined by the accuracy of the temperature control in the cooling process $[1,2]$. Controlling the steel final temperature in the cooling process after rolling has been a representative control problem for metallurgical engineering control and it has attracted considerable attention for the control community. The final temperature, called coiling temperature (CT), determines the physical and mechanical properties of the steel product. However, in recent years higher requirements are proposed that the temperature curve of the whole process needs to be controlled to produce finer microstructure. Since the laminar cooling process only lasts for a very short time and is unidirectional, in practice the model predictive control (MPC) is the most widely used to control this process. Before the real-time control, a simulation must be done to calculate the initial inputs to achieve the desired temperature (coiling temperature). Therefore, establishing a model with high precision and efficiency is especially important [3].

There are two kinds of challenges in improving the precision of the target temperature during the control process. One challenge is to build a model with high efficiency and accuracy. There usually exist two different types of models in recent study: the physical model and the statistical model. In physical model, mechanism analysis is generally used to model the laminar cooling process, which is capable of fully reflecting the heat transfer conditions and then outputting relatively precise coiling temperature $[4,5]$. However, the accuracy of this kind of model is difficult to be further improved owing to its nonlinearity, multicoupling, and multivariate parameters. In order to get more accurate results, artificial intelligent method is introduced to model the laminar cooling process [6]. Also, there are many researches using neural network to control the laminar flow cooling process $[1,7]$. Some studies use fuzzy logic to improve the accuracy of model $[5,8,9]$. The disadvantage of this method is that a large 
number of plates have to be cooled for training the neural network before the neural network is ready for use [10]. The accuracy of the statistical model is subject to the numbers of classification. Based on the analysis of those two models, a high efficiency model which combines both the physical model and the statistical model is proposed in this paper to control the laminar cooling process and avoid each natural defect.

Another challenge is to design a high-efficiency control method in laminar cooling process. Many different control methodologies have been attempted; among them the model predictive control is the most common used. For example, Smith predictor control [11], element tracking control [12], self-learning control [13], and adaptive control [14] are employed to control the coiling temperature by using the simplified model. Most existing MPC methods use the thermodynamic model to estimate the spatial distribution of strip temperature and get a high precision of CT $[2,15]$. In recent year, some of the scholars present various effective approaches that attempt to control the cooling rate and cooling curve. Literature works [16-18] try to use distribute model predictive control to design a supervisory controller regulating the temperature curve. In [19] distributed and horizonvarying model predictive control is applied to control the cooling rate and the fine temperature and gets a very good performance. However, those works are mostly verified in simulation or in the laboratory condition, no production results, and metal crystal detection is performed to verify the effectiveness. In the manufactory, the compute ability of control computer is usually not powerful enough to handle so many matrixes in one control cycle. To control the temperature curve of the whole process, an effective method should be designed to utilize in the industrial current environment without large-scale reconstruction or upgrade project. Besides, it is well known that controlling the coiling temperature curve dropping along a designed optimal temperature can produce high quality of steel plate [8, 17-19]. However, in the manufactory, the temperature curve in the runout table usually is ignored, since controlling the final temperature to match the target temperature could get good steel. Furthermore, based on the existing equipment in the manufactory, the target temperature curve is impossible to control.

Motivated by these recent developments in laminar cooling control strategy and the demand of the industry production, this paper presents a novelty modeling method and a GPC-PID based control strategy for computational and practical reason which could enhance the precision and flexibility of the manufactory control system. Developing an integrated modeling method and a controller for easy tuning and implementation are what we focus on most. While similar models and controls have been used and reported in the literature for laminar cooling process control, the novelty of the approach presented in this work lies in the following aspects. (a) The intelligent TS fuzzy model proposed combines the advantage of the data model and the physical model by adding the physical model with self-learning ability. (b) The coiling temperature and the temperature curve could be controlled in one control method and could be chosen based on the demand. (c) The MPC type of control method contains both the CARIMA model based on stable point and the physical model of the whole process, and they are coordinated to be employed in the different steps of the control. (d) A practical and effective solution is provided for the using of the control strategy in the product line by the current condition without large-scale redevelopment of the control system in production line.

The contents are organized as follows. Section 2 first describes the mechanism analysis and the method to build the physical model and then presents the intelligent modeling strategy of laminar cooling process. Section 3 presents the TS modeling and recognition method, and a data processing technology of the intelligent model is deduced. Section 4 describes that the control strategy of the laminar cooling process to regulate the temperature curve is designed by setting subgoals along the production line and controlling the subgoals. The GPC-PID control algorithm is derived and provides a computing algorithm. The simulation results and the experimental validation of both model and control method are summarized in Section 5, followed by the conclusion in Section 6.

\section{Intelligent Modeling}

2.1. Mechanism Analysis. The laminar cooling process is illustrated in Figure 1. A laminar flow cooling process refers to a process in which rolled steel plates cool down in a laminar flow cooling zone; after that process the steel plate is cooled at preset temperature. The final temperature is also called the cooling temperature. The laminar cooling process is a very important part of iron-making industry to product high quality steel plate. It is used to cool a strip from a high temperature about $800-1000^{\circ} \mathrm{C}$ down to a cooling temperature of roughly $400-680^{\circ} \mathrm{C}$ in the runout table, according to the steel grade and varieties. The runout table is about $145 \mathrm{~m}$ in length and 80 groups of spray headers are installed above and below it. The first 64 groups headers are for the main cooling section and the last 16 groups are for the fine section. When the steel plate is about to be cooled, firstly it is cooled by the main section to nearly the target temperature; then the fine section cools it to the target temperature more accurately. There are only 4 pyrometers located along the runout table, because in the cooling process a large amount of water vapor floating above the steel makes it impossible for the noncontact infrared sensor to measure the real temperature of the plate. The temperature could only be measured when the steel plate is out of the water.

The laminar flow is cooled through various means, such as water cooling heat transfer, air convection heat dissipation, thermal radiation dissipation, and phase change latent heat and the velocity of steel plates and spayed water quantum are controllable in the cooling process. It is important to figure out the extent to which each influencing factor may affect the laminar cooling process by using the laminar cooling production data and conventional laminar flow cooling model. Table 1 lists the heat dissipation amount of different kinds of $1000 \mathrm{~kg}$-weighted steel plates and their mean value.

From Table 1 and Figure 2 it can be seen that although certain amount of heat is released in phase change of steel plates, heat dissipation takes the main role in laminar flow cooling process. As being calculated, the heat transferred by 
TABLE 1: The composition of heat release.

\begin{tabular}{lcccc}
\hline Total heat release & Thermal radiation & Water cooled heat & Air cooled heat & Else \\
\hline $100 \%$ & $6.4 \%$ & $82.6 \%$ & $7.1 \%$ & $3.9 \%$ \\
\hline
\end{tabular}

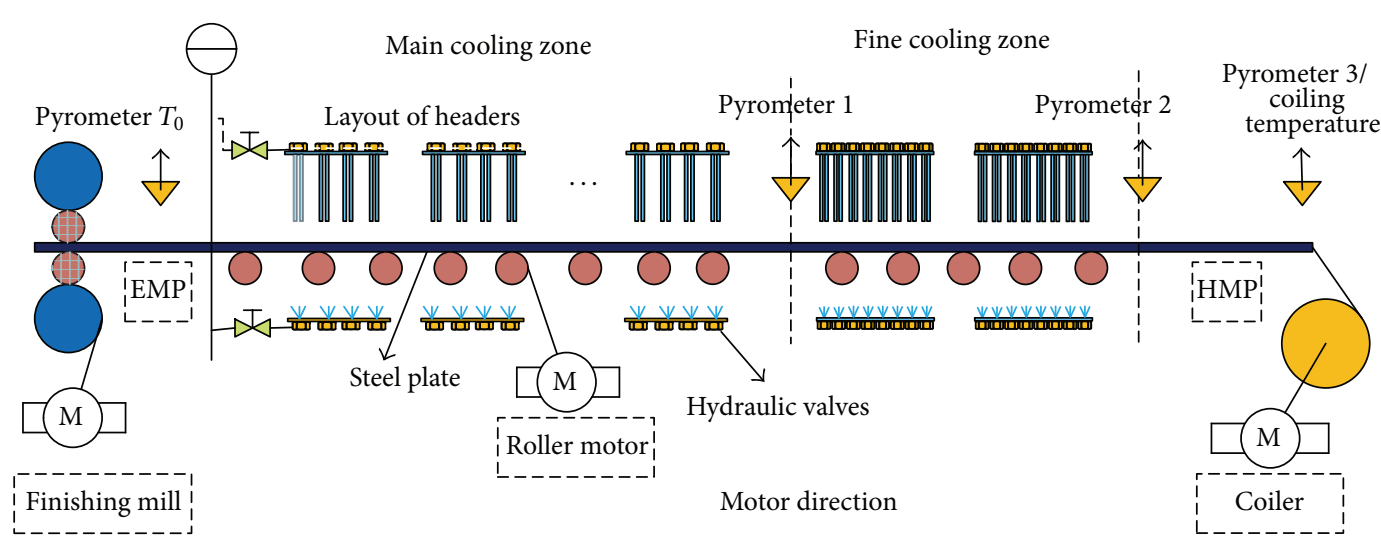

FIgURE 1: The process of the laminar cooling.

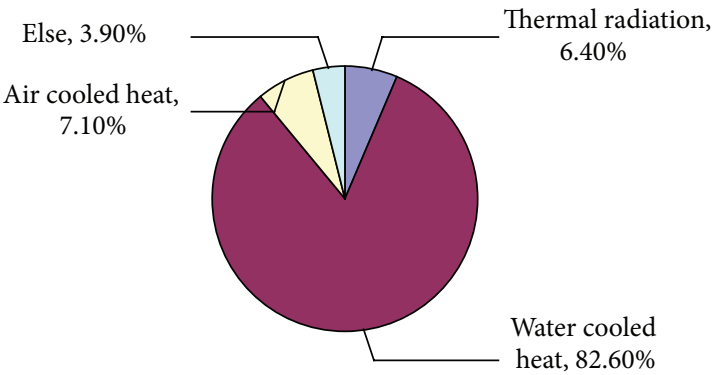

$\begin{array}{ll}\square \text { Thermal radiation } & \square \text { Air cooled heat } \\ \square \text { Water cooled heat } \quad \square \text { Else }\end{array}$

FIGURE 2: The composition of heat release.

water cooling accounts for over $86 \%$ of the total heat dissipation. However, in a laminar flow cooling process, only water cooling heat transfer is controllable by adjusting the flux of water and water cooling time. Therefore, except for water cooling transferred heat, the heat dissipated through other means can be replaced by a theoretical value and its difference from the actual quantity can be considered as a part of water cooling transferred heat. As long as the water cooling transferred heat quantum is calculated reasonably, we can get relatively accurate total heat dissipation and curl temperature:

$$
d Q_{c}=-F \cdot \alpha \cdot\left(T_{s}-T_{w}\right) \cdot d \tau,
$$

where $d Q_{c}$ is the amount of heat loss through convection at unit time, $\mathrm{J} / \mathrm{s}$, including heat losses through water-cooling and air convection; $T_{s}$ is strip temperature, ${ }^{\circ} \mathrm{C} ; T_{w}$ is the cooling water temperature, ${ }^{\circ} \mathrm{C} ; F$ is the contact surface area between the plate and the cooling water, $\mathrm{m}^{2} ; d \tau$ is the contact cooling time, s; $\alpha$ is the heat convection constant, representing the heat exchange intensity at unit area, $\mathrm{W} /\left(\mathrm{m}^{2} \cdot \mathrm{K}\right)$.

According to formula (1), the key parameter affecting water cooling heat dissipation is water cooling heat transfer coefficient $a_{w}$, which is temperature-dependent. Since temperature is not a constant, it is very hard to calculate this coefficient accurately. In addition, subject to the influence of water temperature and the movement of steel plate, it is nearly unrealistic to determine water cooling heat transfer coefficient by one formula only. In view of these, we use TS model method of water cooling heat transfer coefficient to solve the problems described above.

2.2. Modeling Structure. The intelligent model built in this paper refers to the physical model and combines with the data processing method to structure a kind of model which owns data self-learning ability. The model requires two aspects performances, since the laminar cooling process is largescale, short-time, nonlinear characteristics. Firstly, based on the process inputs, the model should calculate the strip temperature accurately, in order to provide the initial setting of the production line. Secondly, the production line is so rapid that fast calculation of the model is needed; consequently the structure of the model should be simple and efficient. The novel type of modeling strategy for laminar cooling process is shown in Figure 3.

The intelligent model contains three parts: the mechanism model, the TS Fuzzy model, and the self-learning model. The mechanism model is the traditional model without the water cooling heat transfer coefficient which is determined by the TS fuzzy model. The intelligent model tries to use the output of the TS fuzzy model to substitute the water cooling heat transfer coefficient function. The self-learning model processes data collected from the production line to identify the parameter of the TS model. A database is 


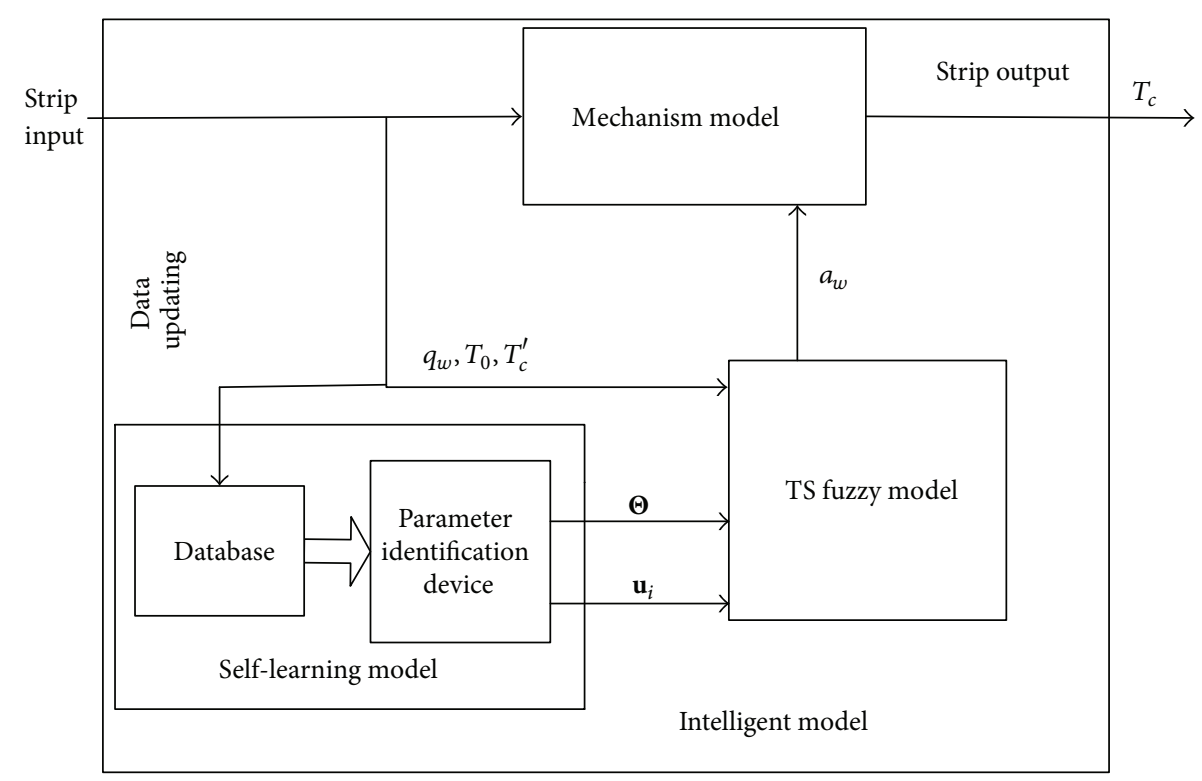

FIGURE 3: Intelligent model structure diagram.

included in the model of the self-learning model which contains sets of newest data collected from the product line. The self-learning model identifies the TS fuzzy parameters at each identification period and transfers them to the TS fuzzy model. Then, the fuzzy model calculates $a_{w}$ which is the most important parameter in mechanism model to get the strip output.

In TS fuzzy model, offline and online methods work together. Offline method is used to get initial parameters with massive data; online method continuously collects the producing data of laminar flow cooling process and updates the parameters of TS fuzzy model to make it adaptive to the product line. In this way, our intelligent model acquires self-study ability.

Although the TS fuzzy model is rapid and accurate, it needs many pieces of data to adjust the model. At the start of the calculation, the TS fuzzy model's precision cannot meet the need of the product. In order to increase the robustness of the system, two complementary strategies are introduced. Besides the fuzzy model, the improved method of the traditional equation is used. The traditional equation of the water cooling heat transfer coefficient cannot adjust its parameters although the production environment is constantly changing, but it is robustness. Once the equation parameters are determined, it could immediately calculate the output according to the input. Based on the above reasons, the TS fuzzy model is combined with the improved equation to achieve the robustness and accuracy of the system.

\section{TS Modeling of the Laminar Cooling}

Actually, TS fuzzy model is a model with a fixed input-output relationship. As long as an appropriate input-output relationship is determined, system recognition can be fulfilled and a TS fuzzy model can be thus obtained [20]. Although water

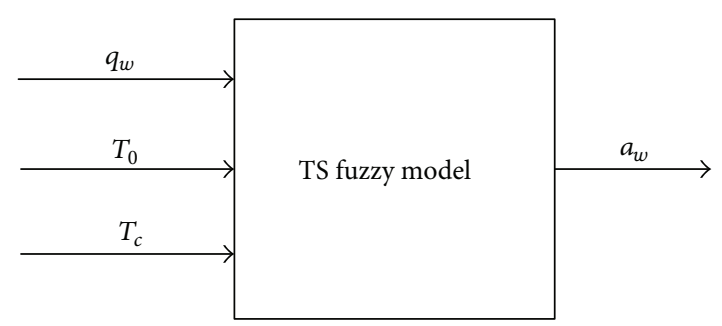

FIGURE 4: Input-output-state relation of the TS Fuzzy model.

cooling heat transfer coefficient is very important, it is difficult to be determined, so TS fuzzy modeling method is utilized to estimate water cooling heat transfer coefficient with real production parameter.

3.1. TS Model. The input-output relationship of water cooling heat transfer coefficient is shown as Figure 4. Provided that the initial temperature $T_{0}$, cooling temperature $T_{c}$, and water density $q_{w}$ of a laminar cooling process are known, the average water cooling heat transfer coefficient can be determined. The input-output relationship of TS fuzzy model is determined by Figure 4.

TS fuzzy model has some advantages: it can describe highly nonlinear complex system with few regular numbers; its structure and parameters can be easily adjusted; it makes system analysis and conventional controller design easier. Due to the fact that it is simple in structure and fast in calculation, TS fuzzy model is chosen by us as a predicting model [20-22].

TS fuzzy model works in this way: (1) create a few fuzzy regulations; (2) each regulation deals with parameters belonging to certain zone; (3) these regulations work together to form an integral fuzzy regulation space; (4) use this fuzzy 


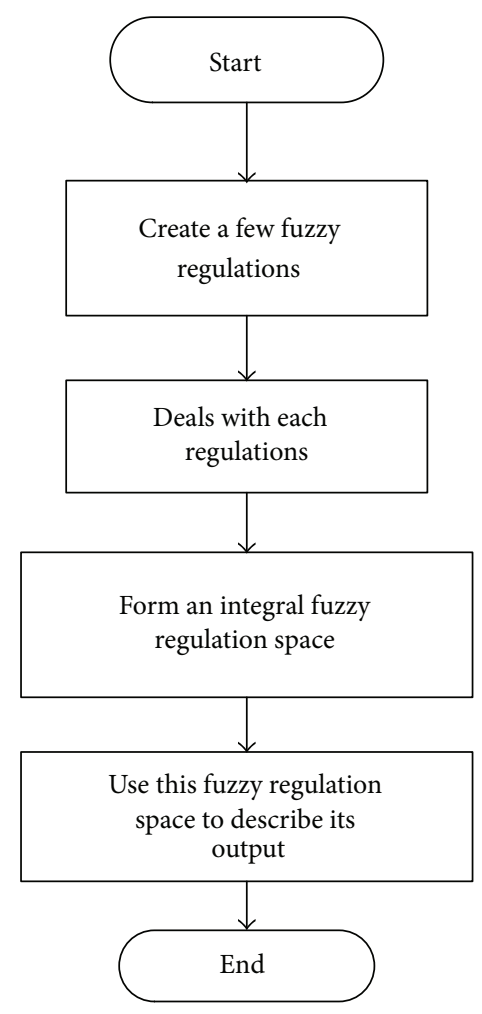

FIGURE 5: The process of the TS Fuzzy model.

regulation space to describe its output. The process of the TS fuzzy model was shown in Figure 5.

The contribution of the $i$ th TS fuzzy rules to the system was expressed in the form of "If. . .Then" statement as follows:

$$
\begin{aligned}
& R^{i}: \text { If } \mathbf{x}_{1}(k) \text { is } \mathbf{A}_{1}^{i} \cdots \text { and } \mathbf{x}_{n}(k) \text { is } \mathbf{A}_{n}^{i} \\
& \quad \operatorname{Then}^{i}(k+1)=p_{0}^{i}+p_{1}^{i} x_{1}+\cdots+p_{n}^{i} \mathbf{x}_{n} ; i=1,2, \ldots, c,
\end{aligned}
$$

where $c$ is the number of fuzzy rules, $n$ is the input variables number of the T-S fuzzy model, $\mathbf{x}_{1}(k), \mathbf{x}_{2}(k), \ldots, \mathbf{x}_{n}(k)$ are the regressive variables consisting of output and input data at the $k$ th instance and before, $\mathbf{x}(k)=\left[x_{1}(k), x_{2}(k), \ldots, x_{n}(k)\right]$ is the input vector of the T-S fuzzy model, $\mathbf{A}_{1}^{i}, \mathbf{A}_{2}^{i}, \ldots, \mathbf{A}_{n}^{i}$ are the membership functions associated with the $i$ th rule, and $p_{0}^{i}, p_{1}^{i}, \ldots, p_{n}^{i}$ are the consequent parameters of the submodel (fuzzy rules) $i$.

We denote $\beta_{i}$ as the fitness grade of the submodel $i$, and thus the model output $\mathbf{y}(k+1)$ at the $(k+1)$ th instance can be calculated as follows [21]:

$$
\begin{aligned}
& \mathbf{y}(k)=\sum_{i=1}^{c} \beta_{i} \mathbf{y}^{i}(k)=\sum_{i=1}^{c} \beta_{i}\left(p_{0}^{i}+\cdots+p_{n}^{i} \mathbf{x}_{n}(k)\right) \\
& =\sum_{i=1}^{c}\left(p_{0}^{i}+\cdots+p_{n}^{i}\right)\left(\beta_{i}+\cdots+\beta_{i} \mathbf{x}_{n}(k)\right)^{T}, \\
& \boldsymbol{\Theta}(k)=\left[\boldsymbol{\theta}_{1}, \boldsymbol{\theta}_{2}, \ldots, \boldsymbol{\theta}_{r}\right]^{T}=\left[\mathbf{p}_{10}, \mathbf{p}_{20}, \ldots, \mathbf{p}_{c 0}, \mathbf{p}_{11}, \mathbf{p}_{21}, \ldots,\right. \\
& \left.\mathbf{p}_{c 1}, \ldots, \mathbf{p}_{c n}\right]^{T} ;
\end{aligned}
$$

$$
\begin{aligned}
& \boldsymbol{\Phi}(k)=\left[\beta_{1}, \ldots, \beta_{c}, \beta_{1} \mathbf{x}_{1}(k), \ldots, \beta_{c} \mathbf{x}_{1}(k), \ldots, \beta_{1} \mathbf{x}_{n}(k), \ldots,\right. \\
& \left.\beta_{c} \mathbf{x}_{n}(k)\right]^{T},
\end{aligned}
$$

where $r=c \cdot(n+1)$; then we can get

$$
\mathbf{y}(k)=\boldsymbol{\Phi}(k)^{T} \times \Theta(k) .
$$

Generally speaking, the antecedent structure identification is completed through fuzzy clustering based on the principle of a fuzzy C-mean (FCM) algorithm and the consequent parameters are identified according to the least squares method [22].

3.2. TS Model Recognition. For a TS fuzzy model, the most important thing is to acquire antecedent and consequent parameters. The consequent parameters are acquired by fuzzy cluster method based on fuzzy $C$ mean value algorithm, and consequent parameters are obtained with least squared method.

Follow the steps below to recognize antecedent and consequent parameters by inputting $\mathbf{x}(k)$ and $\mathbf{y}(k+1)$ :

(1) Use $C$ cluster algorithm to recognize the subordinate degree function $\mathbf{u}_{i}$ of $\mathbf{x}(k)$.

(2) When the input equals $\mathbf{x}(k)$, the fitness of the $i$ th regulation to the system output can be calculated by

$$
\beta_{i}=\sum_{j=1}^{c}\left(\frac{u_{i}}{u_{j}}\right), \quad i=1,2, \ldots, c .
$$

Its vector can be calculated by

$$
\begin{aligned}
& \boldsymbol{\Phi}(k) \\
& \quad=\left[\beta_{1}, \ldots, \beta_{c}, \beta_{1} x_{1}(k), \ldots, \beta_{c} x_{1}(k), \ldots, \beta_{c} x_{n}(k)\right]^{T} .
\end{aligned}
$$

(3) As $\mathbf{y}(k+1)$ and $\Phi(k)$ are both known quantities, according to formula $\mathbf{y}(k+1)=\boldsymbol{\Phi}(k) \Theta(k)$, we can get

$$
\boldsymbol{\Theta}(k)=\left(\boldsymbol{\Phi}^{T} \boldsymbol{\Phi}\right)^{-1} \boldsymbol{\Phi}^{T} \cdot \mathbf{y}(k+1) .
$$

3.3. Data Processing of the Intelligent Model. The data collected in laminar cooling process may deviate from normal range due to controlling failure or a jammed water valve, so it is necessary to shim the collected production data. After the statistical analysis of laminar flow cooling process data and theoretical analysis, the relationship between production data can be summarized:

$$
\begin{aligned}
& T_{c}=T_{0}-\frac{c \cdot n}{a \cdot h \cdot v}, \\
& R=\dot{T}_{c}=\frac{\Delta t_{b}}{L / v},
\end{aligned}
$$

where $T_{c}$ is the crimp temperature, ${ }^{\circ} \mathrm{C} ; T_{0}$ is the initial temperature, ${ }^{\circ} \mathrm{C}$; $h$ is the plate thickness, $\mathrm{m}$, and $n$ is the number 
TABLE 2: Digital characteristics of the TS fuzzy model.

\begin{tabular}{lccccc}
\hline Number of data & 50 & 200 & 500 & 1000 & 2000 \\
\hline Mean square error $\left({ }^{\circ} \mathrm{C}\right)$ & 53.3 & 32.4 & 15.2 & 7.82 & 6.17 \\
\hline Identification time $(\mathrm{ms})$ & 130 & 233 & 521 & 732 & 1340 \\
\hline
\end{tabular}

of the valves opened; $\Delta t_{b}$ is the temperature drop, ${ }^{\circ} \mathrm{C} ; v$ is the average velocity of the steel plate, $\mathrm{m} / \mathrm{s}, L$ is the length of the product line, $\mathrm{m} ; a, c$ are the coefficient of the production line. If the difference of $T_{c}+R$ obtained by substituting the collected data $n, L, \Delta t_{b}$ into formula from the actual collected data is over $10 \%$, the collected data will be eliminated.

As TS fuzzy model needs to recognize the production data in real time, the more data it gets, the more accurate its output will be. However large amount of data requires large data storage space and long time for data recognizing; therefore, it is necessary to provide a suitable storage space for it. Table 2 shows us the results calculated by a computer with $3.0 \mathrm{GHz}$ CPU, 4 G memory.

Mean square error is calculated by comparing data collected in real time and data generated by model. Recognizing time is the time that MATLAB spends on TS model parameter recognizing. According to the table, when the data reaches 1000 sets, mean square error can be kept less than $10^{\circ} \mathrm{C}$ and calculating time is also acceptable. Increasing more data can no longer obviously improve the accuracy of model, so just keeping 1000 sets of product data is acceptable. Then all the work needed to build the intelligent model was completed. The total process of the intelligent model is shown as Figure 6.

\section{Control System}

In order to improve the quality of the steel plate, the control system in the manufactory needs to be improved to produce higher quality and performance steel plate. The existing method in industrial manufactory tries to control the cooling temperature. The average cooling rate is regarded as the real cooling rate of the steel plate. So the opened header groups $N_{0}$ is computed as follows:

$$
N_{0}=\frac{v_{c}}{l} \cdot \frac{T_{0}-T_{c}}{R_{c}},
$$

where $T_{0}$ is the start temperature, $T_{c}$ is the cooling temperature, $l$ is the length of the runout table, the $v_{c}$ is the average speed of the steel (usually the speed is changing all the time), and $R_{c}$ is the average temperature drop caused by one group of headers.

In manufactory, $N_{0}$ sometimes is given by experienced engineers according by the common configure of one type of steel. In some of more advanced factory, the laminar cooling model induces the engineers to calculate the initial setting of the production line. Although many intelligent cooling models with high accuracy are established and the final temperature of the steel plate is controlled precisely, the cooling rate is not properly handled. Reference [16] presents a kind of distributed model predictive control for plant-wide hotrolled strip laminar cooling process, but the laminar cooling process is very fast, the sampling period only lasts within one

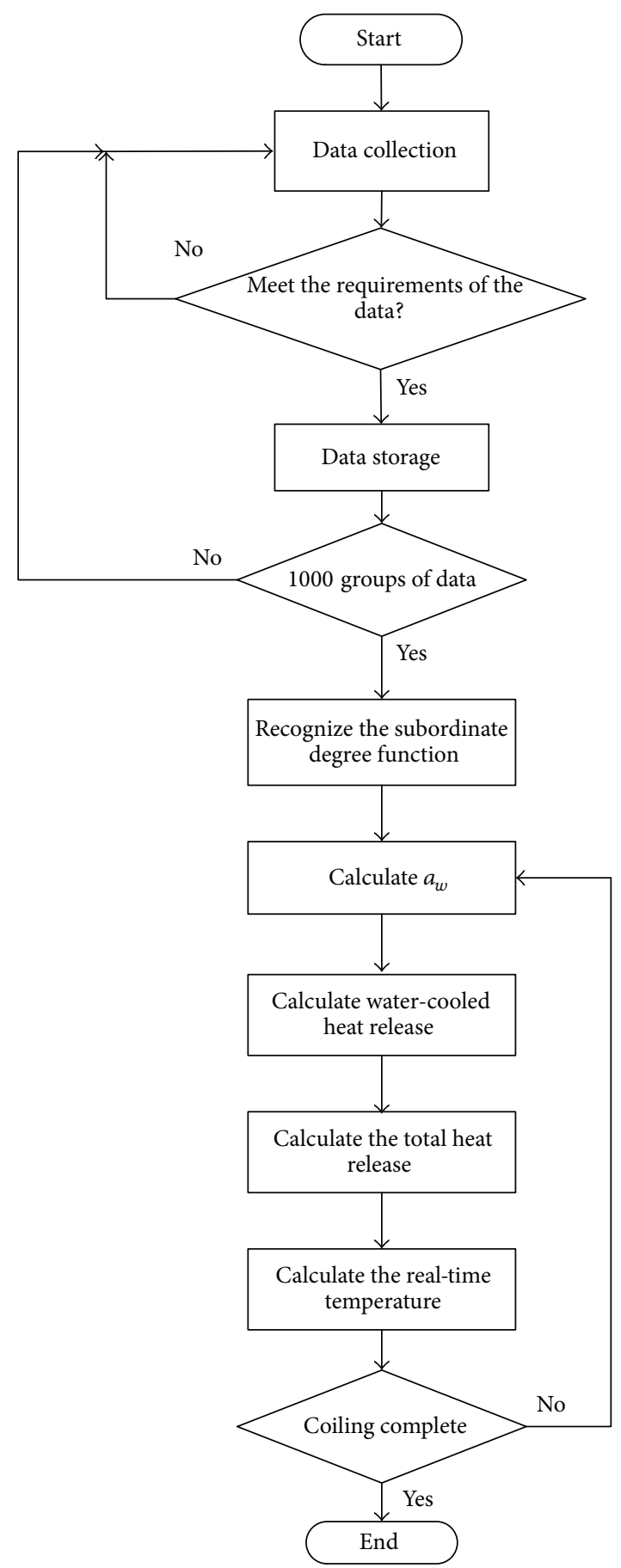

FIGURE 6: The total process of the intelligent model.

second, and the present control computers do not have the ability to handle too many matrices in a single sampling period. A series of high speed and accuracy control strategies is needed to control the whole curve of the cooling temperature.

The control strategy is shown in Figure 7, the model gives the initial setting of the process, and local PID controllers control their local target. If the subtarget temperatures are 


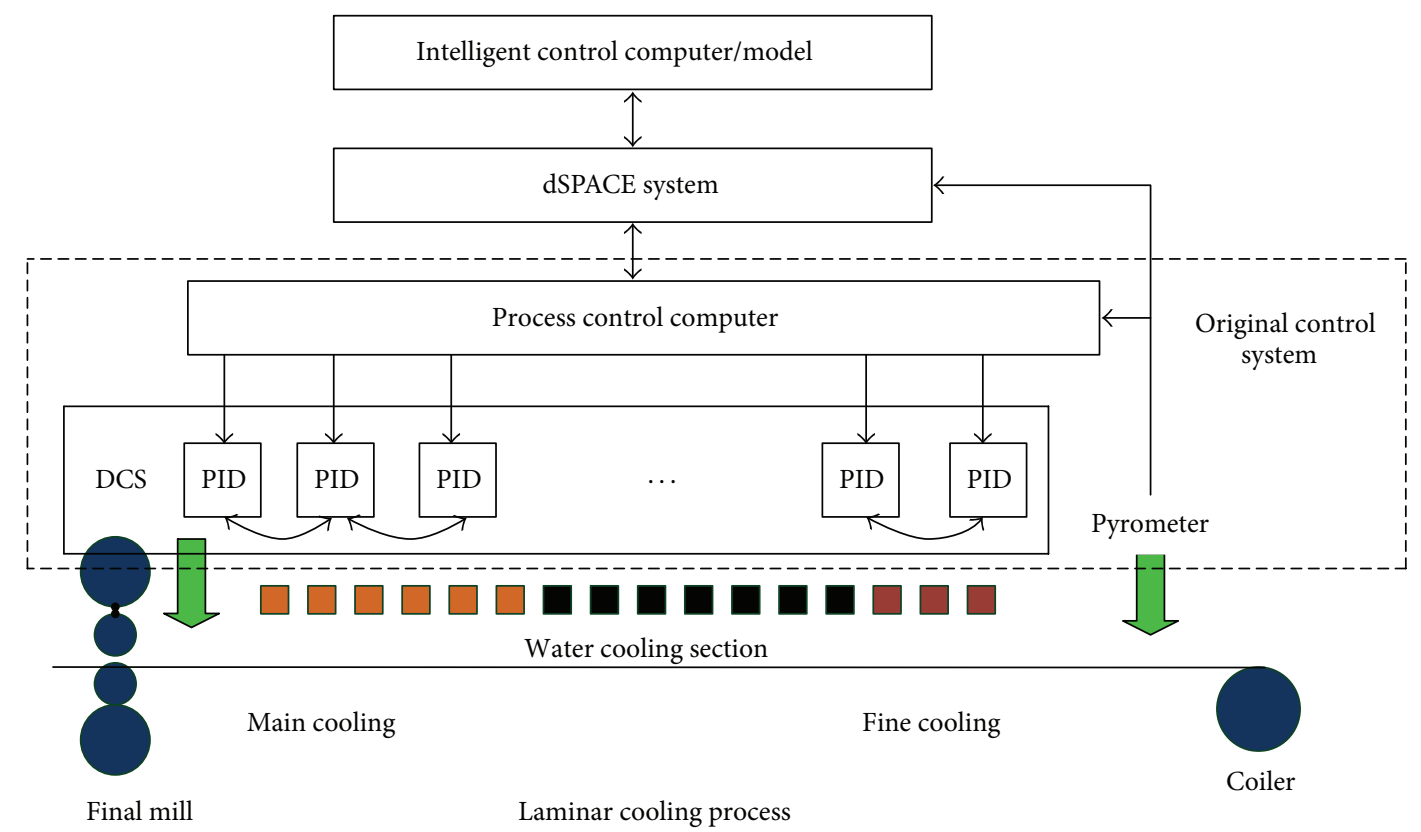

FIgURE 7: The structure of the control system.

properly handled, the steel plate temperature will drop along the setting temperature curve.

4.1. Subgoal Setting. The whole system is divided into $N$ subsystem; the system ranges from 1 to $n$. If the speed is controlled in a constant, the running time is determined by the location. The desired geometrically location-dependent temperatures are selected at the locations $L 1, L 2, L 3, \ldots, L n$ as the reference temperatures with the notation $r=[r 1, r 2, \ldots, r n]$. The process is shown in Figures 8 and 9. When the type of the steel plate is determined, its optimal cooling curve is certain. The discrete reference point $r$ needs to be selected to reflect the characteristics of the optimal cooling curve. The number of sampling points is determined by the need of the control precision. The appropriate number of sampling points is the balance of the quickness and accuracy.

4.2. Submodel. Unlike other kinds of the laminar cooling models, the relationship between the inputs and outputs near the reference temperature are described by the CARIMA model. The steel plate exchanges heat with outside mainly through three ways: heat conduction and thermal radiation and heat convection.

The surface layer is described as follows:

$$
\begin{aligned}
& d Q_{0}=d Q_{\text {radiation }}+d Q_{\text {convection }}+d Q_{0,1}, \\
& d Q_{\text {radiation }}=-A_{r} \cdot \varepsilon \cdot \sigma \cdot\left[\left(T_{s}\right)^{4}-\left(T_{a}\right)^{4}\right] \cdot d t, \\
& d Q_{\text {convection }}=-A_{r} \cdot \alpha \cdot\left(T_{1}-T_{w}\right) \cdot d t
\end{aligned}
$$

$$
\begin{gathered}
c \cdot m \cdot d T=\left\{\lambda \cdot A_{r} \cdot \frac{T_{2}-T_{1}}{h}-A_{r} \cdot \alpha \cdot\left(T_{1}-T_{w}\right)\right. \\
\left.-A_{r} \cdot \varepsilon \cdot \sigma \cdot\left[\left(T_{s}\right)^{4}-\left(T_{a}\right)^{4}\right]\right\} d t .
\end{gathered}
$$

Transform the differential equation into discrete form:

$$
\begin{aligned}
c \cdot m \cdot\left(T_{1}(k+1)-T_{1}(k)\right)=\left\{\lambda \cdot A_{r} \cdot \frac{T_{1}(k)-T_{2}(k)}{h}\right. \\
-A_{r} \cdot \alpha \cdot\left(T_{1}(k)-T_{w}\right)-A_{r} \cdot \varepsilon \cdot \sigma \\
\left.\quad \cdot f\left(T_{1}(k)\right)\right\} d t .
\end{aligned}
$$

The difference between the internal layer and surface layer is no external heat dissipating, only internal levels of heat transfer:

$$
\begin{aligned}
& d Q_{i}=d Q_{i-1, i}+d Q_{i}, \\
& d Q_{i-1, i}=\lambda(T) \cdot A_{r} \cdot \frac{T_{m-1}-T_{m}}{\left(h_{m}+h_{m-1}\right) / 2} \cdot d t, \\
& d Q_{i, i+1}=\lambda(T) \cdot A_{r} \cdot \frac{T_{m+1}-T_{m}}{\left(h_{m+1}+h_{m}\right) / 2} \cdot d t, \\
& c \cdot m \cdot\left(T_{2}(k+1)-T_{2}(k)\right) \\
& \quad=\left\{\lambda \cdot A_{r} \cdot \frac{2 T_{2}(k)-T_{1}(k)-T_{3}(k)}{h}\right\} d t .
\end{aligned}
$$




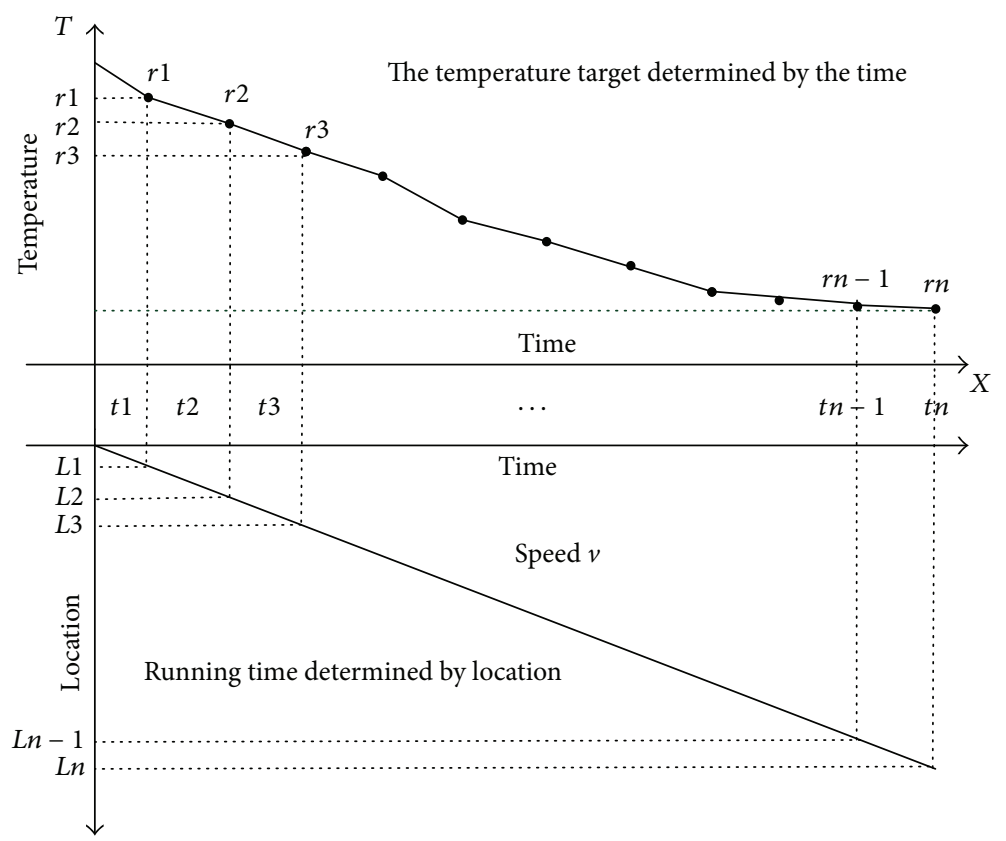

FIGURE 8: Subgoals setting along the running direction.

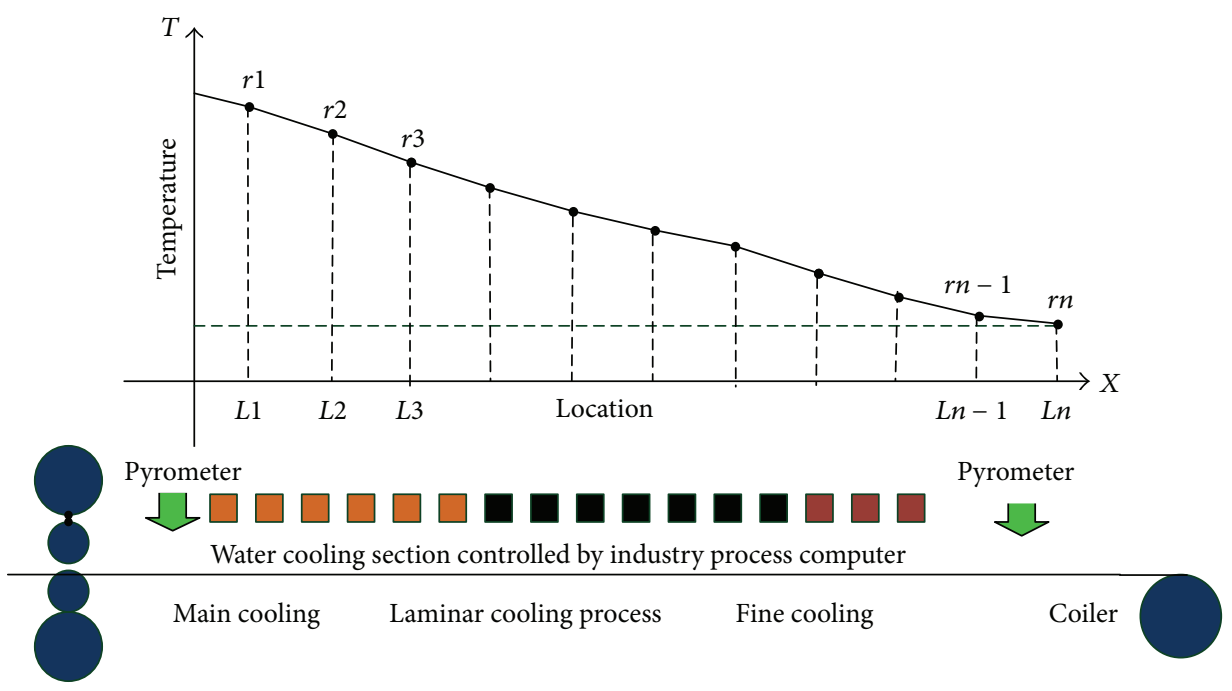

FIGURE 9: Subgoals setting along the cooling process.

Matrix form is described as follows:

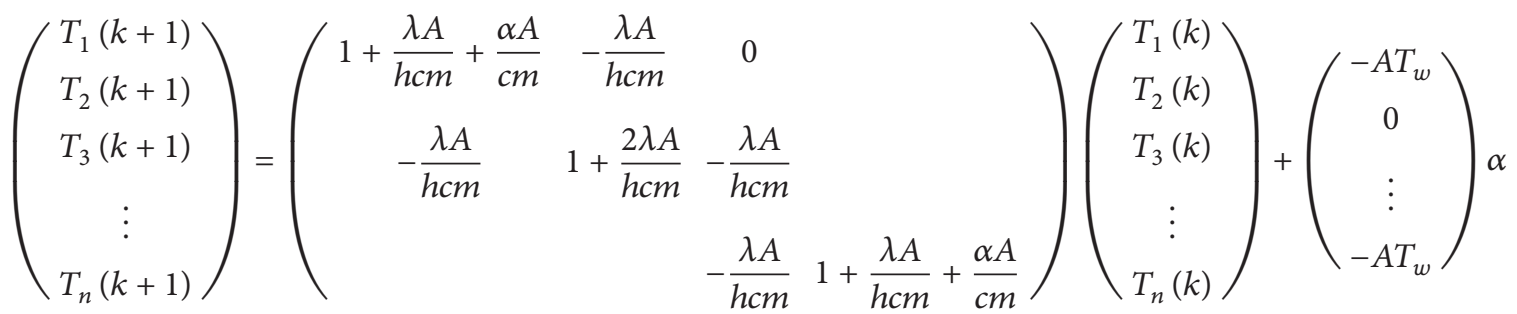

$$
\begin{aligned}
& +\operatorname{A\varepsilon \sigma f}\left(T_{1}(k)\right), \\
& \mathbf{T}(k+1)=\mathbf{M T}(k)+\mathbf{N u}+\boldsymbol{\xi} .
\end{aligned}
$$


Rewriting according to the predictive control equation, we get the following:

$$
\begin{aligned}
\mathbf{T}(k+1) & =\left(\begin{array}{ll}
\mathbf{M} \mathbf{N}
\end{array}\right)\left(\begin{array}{c}
\mathbf{T}(k) \\
\mathbf{u}
\end{array}\right)+\boldsymbol{\xi}, \\
\mathbf{A x}(k+1) & =\mathbf{B u}(t)+\boldsymbol{\xi} .
\end{aligned}
$$

4.3. GPC-PID Control Method. The generalized predictive control (GPC) is chosen as a basis for predictive PID for two major reasons. First, the receding horizon solution of GPC can be described easily in a linear polynomial representation. In comparison, the receding form of DMC is cumbersome because it is based on a convolution model. Second, GPC is a generalized strategy which includes all desirable properties of the industry proven MPC formulations [23]. It is assumed that the plant is adequately represented by the CARIMA model:

$$
\mathbf{A}\left(z^{-1}\right) \mathbf{y}(k)=\mathbf{B}\left(z^{-1}\right) z^{-d} \mathbf{u}(k)+\frac{\mathbf{C}\left(z^{-1}\right) \boldsymbol{\xi}(k)}{\Delta},
$$

where

$$
\begin{aligned}
& \mathbf{A}\left(z^{-1}\right)=1+a_{1} z^{-1}+\cdots+a_{n_{a}} z^{-n_{a}}, \\
& \mathbf{B}\left(z^{-1}\right)=b_{0}+b_{1} z^{-1}+\cdots+b_{n_{b}} z^{n_{b}}, \\
& \mathbf{C}\left(z^{-1}\right)=c_{0}+c_{1} z^{-1}+\cdots+c_{n_{c}} z^{n_{c}},
\end{aligned}
$$

where $z^{-1}$ is the backward shift operator. $\mathbf{y}(t)$ is the plant output or the measured output signal, $\mathbf{u}(t)$ is the control input, $\xi(t)$ is the noise that disturbs the output signal, and $\Delta=1-z^{-1}$.

To derive a GPC law that minimizes the performance index, two Diophantine equations are solved:

$$
\begin{aligned}
1 & =\mathbf{A}\left(z^{-1}\right) \mathbf{E}_{j}\left(z^{-1}\right) \Delta+z^{-j} \mathbf{F}_{j}\left(z^{-1}\right), \\
\mathbf{E}_{j}\left(z^{-1}\right) \mathbf{B}\left(z^{-1}\right) & =\mathbf{G}_{j}\left(z^{-1}\right)+z^{-j} \mathbf{H}_{j}\left(z^{-1}\right),
\end{aligned}
$$

where

$$
\begin{aligned}
& \mathbf{E}_{j}\left(z^{-1}\right)=1+e_{j, 1} z^{-1}+\cdots+e_{j, j-1} z^{-(j-1)}, \\
& \mathbf{F}_{j}\left(z^{-1}\right)=f_{j, 0}+f_{j, 1} z^{-1}+\cdots+f_{j, n_{a}} z^{-n_{a}}, \\
& \mathbf{G}_{j}\left(z^{-1}\right)=g_{0}+g_{1} z^{-1}+\cdots+g_{j-1} z^{-j+1}, \\
& \mathbf{H}_{j}\left(z^{-1}\right)=h_{j, 0}+g_{j, 1} z^{-1}+\cdots+g_{j, n_{b}-1} z^{-n_{b}+1} .
\end{aligned}
$$

The $j$ steps ahead predictive output is given as follows:

$$
\begin{aligned}
\mathbf{y}(t+j)= & \mathbf{G}_{j} \Delta \mathbf{u}(t+j-1)+\mathbf{F}_{i} \mathbf{y}(t)+\mathbf{H}_{j} \Delta \mathbf{u}(t-1) \\
& +\mathbf{E}_{j} \mathbf{w}(t+j) .
\end{aligned}
$$

$\mathbf{E}_{j} \mathbf{w}(t+j)$ is the disturbance signal, and the vector form of the optimal predictive outputs is expressed as follows:

$$
\mathbf{y}=\mathbf{G u}+\mathbf{F} \mathbf{y}(t)+\mathbf{H} \Delta \mathbf{u}(t-1),
$$

where

$$
\begin{aligned}
\mathbf{y}^{T} & =[y(t+1), \ldots, y(t+N)], \\
\mathbf{u}^{T} & =[\Delta \mathbf{u}(t), \ldots, \Delta \mathbf{u}(t+N-1)], \\
\mathbf{F}^{T} & =\left(F_{1}, \ldots, F_{N}\right), \\
\mathbf{H}^{T} & =\left[\mathbf{H}_{1}, \ldots, \mathbf{H}_{N}\right], \\
\mathbf{G} & =\left[\begin{array}{ccccc}
g_{0} & & \cdots & & 0 \\
g_{1} & g_{0} & & \cdots & \\
\vdots & & \ddots & & \\
& \vdots & & & \\
g_{N-1} & g_{N-2} & \cdots & \cdots & g_{0}
\end{array}\right] .
\end{aligned}
$$

The future reference trajectory is defined as $\mathbf{y}_{r}=\left[\mathbf{y}_{r}(k+\right.$ $\left.\left.N_{1}\right), \mathbf{y}_{r}\left(k+N_{1}+1\right), \ldots, \mathbf{y}_{r}\left(k+N_{2}\right)\right]^{T}$.

The GPC control objective is composed of a sum of squares prediction error term and a control action penalty term given by

$$
\begin{aligned}
J= & E\left\{\sum_{j=1}^{N}\left[\mathbf{y}^{0}(t+j)-\mathbf{y}_{r}(t)\right]^{2}\right. \\
& \left.+\sum_{j=1}^{N} \mathbf{Q}_{j}\left(z^{-1}\right)[\Delta \mathbf{u}(t+j-1)]^{2}\right\},
\end{aligned}
$$

where $\mathbf{y}_{r}$ is the setpoint, $N$ is the control horizon, and $\mathbf{Q}$ is the control weight:

$$
\begin{aligned}
& \mathbf{Q}_{1}\left(z^{-1}\right)=q_{0}^{1}+q_{1}^{1} z^{-1}+\cdots+q_{n_{b}}^{1} z^{-n_{b}}, \\
& \mathbf{Q}_{j}\left(z^{-1}\right)=q_{0}^{j} \quad j=2,3, \ldots, N .
\end{aligned}
$$

The vector form is described as follows:

$$
J=E\left\{\left(\mathbf{y}-\mathbf{y}_{r}\right)^{T}\left(\mathbf{y}-\mathbf{y}_{r}\right)+\mathbf{u}^{T} \mathbf{Q} \mathbf{u}\right\} .
$$

The optimal solution with respect to $\Delta \mathbf{u}$ is obtained as

$$
\begin{aligned}
\Delta \mathbf{u}= & \left(\mathbf{G}^{T} \mathbf{G}+\lambda \mathbf{I}\right)^{-1} \mathbf{G}^{T}\left(\mathbf{y}_{r}-\mathbf{y}_{1}\right), \\
\mathbf{u}(k)= & \mathbf{u}(k-1) \\
& +[1,0, \ldots, 0]\left(\mathbf{G}^{T} \mathbf{G}+\lambda \mathbf{I}\right)^{-1} \mathbf{G}^{T}\left(\mathbf{y}_{r}-\mathbf{y}_{1}\right) .
\end{aligned}
$$

The input $\Delta \mathbf{u}(t)$ is rewritten by the following:

$$
\begin{aligned}
\Delta \mathbf{u}(t)= & \sum_{j=0}^{N} p_{j} \mathbf{y}_{r}(t)-\sum_{j=1}^{N} p_{j} \mathbf{F}_{j}\left(z^{-1}\right) \mathbf{y}(t) \\
& -\sum_{j=1}^{N} p_{j} \mathbf{H}_{j}\left(z^{-1}\right) \Delta \mathbf{u}(t-1) .
\end{aligned}
$$


The incremental discrete PID control law is developed by starting with the noninteracting continuous algorithm given by

$$
\begin{aligned}
u(t) & =k_{p}\left[e(t)+\frac{1}{T_{I}} \int_{0}^{t} e(t) d t+T_{D} \frac{d e(t)}{d t}\right] \\
& =k_{p} e(t)+k_{I} \int_{0}^{t} e(t) d t+k_{D} \frac{d e(t)}{d t}
\end{aligned}
$$

where $\mathbf{u}(t)$ is the input of the control system, $k_{p}$ is the proportional constants, $k_{I}$ is the integral constants, $k_{D}$ is the derivative constants, and $e(t)$ is the error. The transfer function can be written as follows:

$$
G_{c}(s)=\frac{U(s)}{E(s)}=\frac{k_{p} T_{D} T_{I} s^{2}+k_{p} T_{I} s+k_{p}}{T_{I} s} .
$$

A first-order discretization of the results is given in the following discrete control law:

$$
\begin{aligned}
u(t) & =u(t-1)+p_{0} e(t)+p_{1} e(t)+p_{2} e(t-2), \\
G_{c}(z) & =\frac{p_{0}+p_{1} z^{-1}+p_{2} z^{-1}}{1-z^{-1}} .
\end{aligned}
$$

Compared with (26), we have the following:

$$
\begin{aligned}
& p_{0}=k_{p}+k_{I}+k_{D}=k_{p}+\frac{k_{p} T_{s}}{T_{I}}+\frac{k_{p} T_{D}}{T_{s}}, \\
& p_{1}=-k_{p}-2 k_{D}=-k_{p}-\frac{2 k_{p} T_{D}}{T_{s}}, \\
& p_{2}=k_{D}=\frac{k_{p} T_{D}}{T_{s}} .
\end{aligned}
$$

Discrete expression of PID controller is described as follows:

$$
L\left(z^{-1}\right) u(t)=M\left(z^{-1}\right) y_{r}(t)-N\left(z^{-1}\right) y(t) .
$$

The control law of the GPC is

$$
\begin{aligned}
& \Delta u(t) \\
& =\sum_{j=0}^{N} p_{j} y_{r}(t)-\sum_{j=1}^{N} p_{j} F_{j}\left(z^{-1}\right) y(t) \\
& -\sum_{j=1}^{N} p_{j} H_{j}\left(z^{-1}\right) \Delta u(t-1), \\
& L(z)=1-z^{-1}, \\
& M\left(z^{-1}\right)=\sum_{j=1}^{N} p_{j}, \\
& N\left(z^{-1}\right)=\sum_{j=1}^{N} p_{j} F_{j}\left(z^{-1}\right),
\end{aligned}
$$

$$
\begin{aligned}
& \sum_{j=1}^{N} p_{j} H_{j}\left(z^{-1}\right) \Delta u(t-1)=p_{1} \sum_{i=1}^{N} q_{i}^{1} \Delta u(t-i), \\
& q_{i}^{1}=\frac{1}{p_{1}} \sum_{1}^{N} p_{j} h_{i-1}^{j}, \quad i=1,2, \ldots, n_{b} .
\end{aligned}
$$

According to the result of the above derivation, the PID parameters can be rewritten, to get the self-tuning PID controller parameters:

$$
u(t)=\frac{k_{I}}{1-z^{-1}} e(t)-\left[k_{p}+\left(1-z^{-1}\right) k_{D}\right] y(t) .
$$

Then get the following results:

$$
\begin{aligned}
& \left(1-z^{-1}\right) u(t)=k_{I} y_{r}(t) \\
& -\left[k_{I}+\left(1-z^{-1}\right) k_{p}+\left(1-z^{-1}\right) k_{D}\right] y(t) \\
& =k_{I} y_{r}(t) \\
& -\left[\left(k_{I}+k_{p}+k_{D}\right)-\left(k_{p}+2 k_{D}\right) z^{-1}+k_{D} z^{-2}\right] \\
& \cdot y(t) .
\end{aligned}
$$

Compare the PID with GPC:

$$
\begin{aligned}
L\left(z^{-1}\right) & =1-z^{-1}, \\
M\left(z^{-1}\right) & =k_{I}=\sum_{j=1}^{N} p_{j}, \\
N\left(z^{-1}\right) & =\left(k_{I}+k_{p}+k_{D}\right)-\left(k_{p}+2 k_{D}\right) z^{-1}+k_{D} z^{-2} \\
& =\sum_{j=1}^{N} p_{j} F_{j}\left(z^{-1}\right) \\
& =\sum_{j=1}^{N} p_{j} f_{0}^{j}+\sum_{j=1}^{N} p_{j} f_{1}^{j} z^{-1}+\sum_{j=1}^{N} p_{j} f_{2}^{j} z^{-2} .
\end{aligned}
$$

The PID parameters are calculated as follows [24, 25]:

$$
\begin{aligned}
k_{p} & =-\sum_{j=1}^{N} p_{j}\left(f_{1}^{j}+2 f_{2}^{j}\right), \\
k_{I} & =\sum_{j=1}^{N} p_{j}, \\
k_{D} & =\sum_{j=1}^{N} p_{j} f_{2}^{j} .
\end{aligned}
$$


The optimal control input can be calculated by

$$
\begin{aligned}
\mathbf{u}(t)= & \mathbf{u}(t-1)-\sum_{j=1}^{N} p_{j}\left(f_{1}^{j}+2 f_{2}^{j}\right)[\mathbf{y}(t-1)-\mathbf{y}(t)] \\
& +\sum_{j=1}^{N} p_{j}\left[\mathbf{y}_{r}(t)-\mathbf{y}(t)\right] \\
& +\sum_{j=1}^{N} p_{j} f_{2}^{j}[2 \mathbf{y}(t-1)-\mathbf{y}(t-2)-\mathbf{y}(t)] .
\end{aligned}
$$

Finally, the GPC-PID control algorithm is gotten:

(1) Firstly, the model of the control plate needs to be identified to get $\mathbf{A}\left(z^{-1}\right), \mathbf{B}\left(z^{-1}\right)$ in the CARIMA model.

(2) Calculate the $\mathbf{G}_{j}\left(z^{-1}\right), \mathbf{F}_{j}\left(z^{-1}\right)$ by solving the Diophantine equation.

(3) Then, the control input $\Delta \mathbf{u}=\left(\mathbf{G}^{T} \mathbf{G}+\lambda \mathbf{I}\right)^{-1} \mathbf{G}^{T}\left(\mathbf{y}_{r}-\mathbf{y}_{1}\right)$.

(4) Compute the PID control parameters $k_{I}, k_{D}, k_{p}$.

(5) Get the control input $\mathbf{u}(t)$.

Now the design of GPC-PID control method for laminar cooling process is completed and some experiments are presented in the next section.

\section{Validation of the Modeling and Control Method}

5.1. Modeling. The model is built in MATLAB/Simulink environment, and the results are calculated by a computer with 3.0 GHz CPU, 4 G memory.

5.1.1. Validation of the System Model. To test the validation of this method, some experiments are conducted using real industrial data. The type of steel X80 is chosen to validate the model.

Use the method described above to model a laminar flow cooling process, filter abnormal data, recognize parameter with 1000 sets of effective data, substitute the parameter into TS fuzzy model, and then collect 300 sets of production data to verify the output results.

5.1.2. Comparison between the Traditional Model and Intelligent Model. Figures 10 and 11 compare the results of the conventional mechanism model data and TS model data with real producing data, respectively. It is obvious that TS fuzzy model gives us a more accurate result than conventional mechanism model in Figure 12.

From Table 3, the TS fuzzy model can largely improve the accuracy of a laminar flow cooling model. The cooling temperature predicted by TS fuzzy model is matched well with real production data, with the difference between them kept less than $10^{\circ} \mathrm{C}$. Also, the error between TS modeling data and real production data is largely reduced; and mean square error can be reduced by $50 \%$ compared to conventional model.
TABLE 3: The comparison of the two types of model.

\begin{tabular}{lcc}
\hline Method & $\begin{array}{c}\text { Maximum error } \\
\left({ }^{\circ} \mathrm{C}\right)\end{array}$ & $\begin{array}{c}\text { Mean square error } \\
(\mathrm{MSE})\left({ }^{\circ} \mathrm{C}\right)\end{array}$ \\
\hline Mechanism model & 17.3 & 9.32 \\
Intelligent model & 8.8 & 4.42 \\
\hline
\end{tabular}

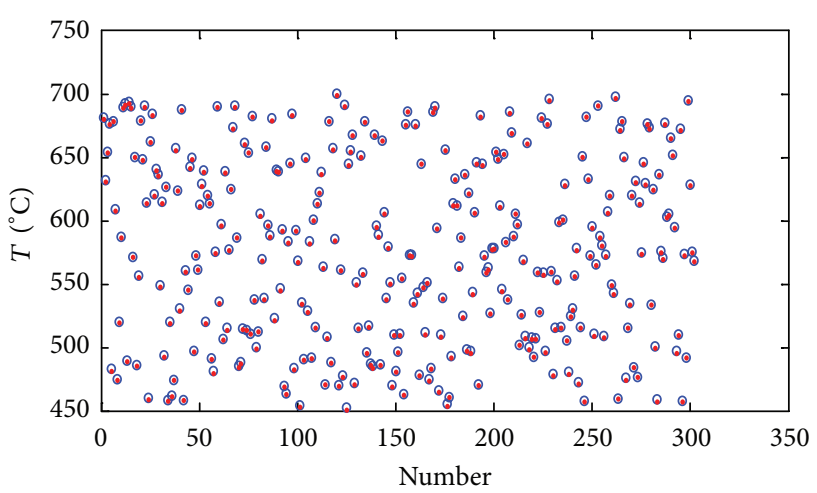

- New model data

- Production data

FIgURE 10: The comparison of the model data and the product data of the mechanism model.

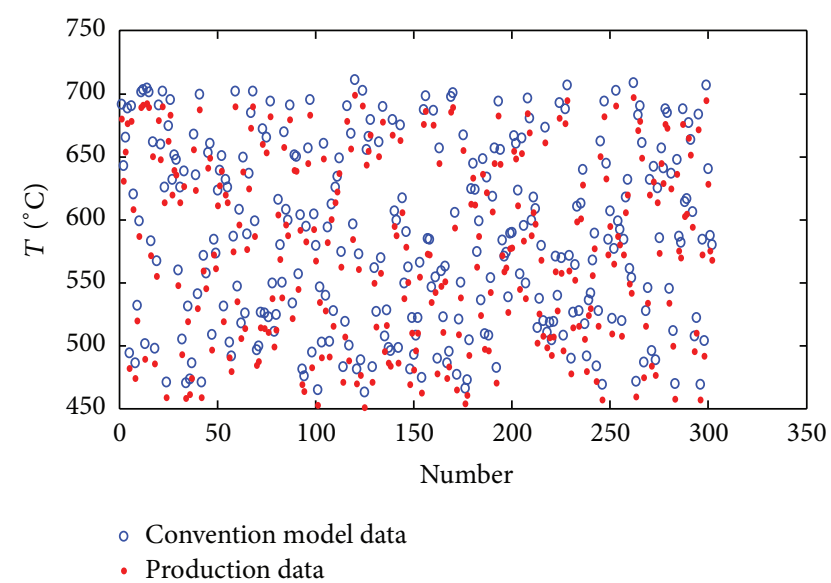

FIgURE 11: The comparison of the model data and the product data of the intelligent model.

5.1.3. Output of the Intelligent Model. The intelligent model is validated in the last section, so the output could reflect the reality of the laminar cooling process. Figure 13 shows the whole temperature curve of the steel along the thickness direction. The initial temperature is about $800^{\circ} \mathrm{C}-900^{\circ} \mathrm{C}$; when the steel plate enters the main cooling zone the temperature of the surface layer will largely drop, but the inside layer's temperature is still very high because the heat inside should be release through conduct with the outside layer. So the internal layer's temperature will be hysteretic compared with the surface layers. There will be internal and external temperature difference when the steel enters the cooling zone. On the other hand, when the plate is running out of the cooling zone, the cooling rate of the surface will decrease, 


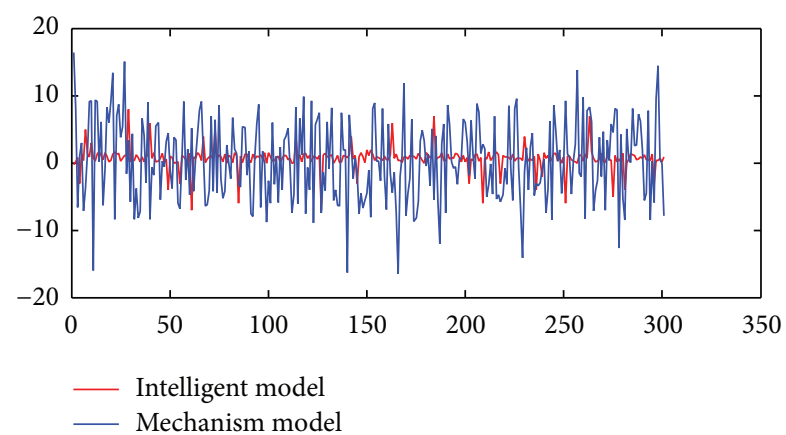

Figure 12: The error comparison between the two models.

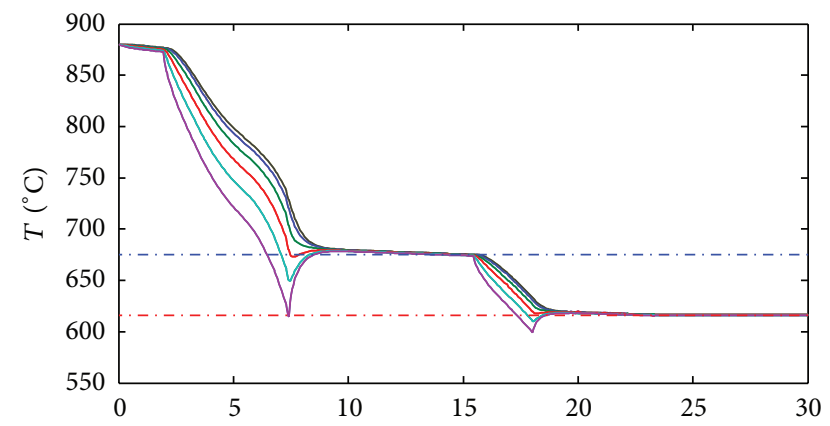

FIGURE 13: The temperature curve of different layers.

but the internal is still very hot, so the heat flows from internal layer to external layer. The phenomenon will show that the internal temperature still declines while the external temperature rises. This phenomenon is clearly expressed in Figure 13.

The intelligent model could compute the temperature differences between the internal and the external layer of the plate shown in Figure 14(a). Figure 14(b) shows the average temperature curve of the steel. The model also could calculate other parameters difficult to be directly measured in the laminar cooling process, shown in Figures 14(c)-14(f).

\subsection{Control Strategy}

5.2.1. Experimentation. To illustrate the performance of proposed modeling and control method, application of this method to laminar cooling process test is performed in one steel testing product line in Hubei, China. The control system is shown in Figure 15. In the factory, the initial control system is very difficult for the improvement of the equipment and is not convenient for the use of the new control algorithm, since the Distributed Control System (DCS) could not process the matrix. As a consequence, new equipment needs to be introduced to solve that disadvantage.

The dSPACE control system, DS1103 PPC Controller Board, is utilized to add the intelligent model to the control system without large-scale reconstruction of the initial control system. The controller board is designed to meet the requirements of modern rapid control prototyping and is highly suitable for applications. The DS1103 is an all-rounder in rapid control prototyping. It can be mounted in a dSPACE
Expansion Box or dSPACE AutoBox to test new control functions in a laboratory or directly in the product line. The dSPACE 1103 PPC system has a PowerPC Type CPU, PPC $750 \mathrm{GX}$, with CPU clock $1 \mathrm{GHz}$. The unparalleled number of I/O interfaces makes the DS1103 a versatile controller board for numerous applications.

The initial control system only provides several interfaces to collect data provided by the intelligent model running in the dSPACE system. The dSPACE system could run the intelligent model; meanwhile the process is going to exchange information with the laminar cooling process. At the start of the cooling process, the intelligent model calculates the initial input of the control system based on the known initial information of the production line, such as the beginning temperature of the steel plate, the target temperature, the thickness, the type, and the grade of the steel. Before the laminar cooling process is ongoing, the intelligent model calculates the parameters of the CARIMA model and the PID parameters of all the temperature control points and then passes data to the industrial computer and PLC controller. The PID parameters will not be changed in one cooling process of one type of steel. Although processing the matrix in GPC algorithm is a very complex work, it is not calculated every control period. Instead, the control outputs are based on the PID control and other kinds of control methods such as feedforward and feedback control. In this way the control strategy will be robust and will be easily handled for the engineers.

5.2.2. Performance of Proposed Controller. In the manufactory, the control target of the laminar cooling contains two related aspects: the cooling temperature (CT) and the whole temperature curve (TC). The CT is the last temperature point in TC which is important for the cooling, and the TC plays important role in the construction of the microstructure of the steel. Figure 16 shows that the CT is well controlled in the manufactory by the strategy proposed above. The control variables are shown in Figure 17. Figure 18 shows the temperature curve dropping along the subgoals.

5.2.3. Physical Verification. To validate the control method, a metallography detection is carried on in a research institute in Wuhan, China. The WL510 type of steel is selected and the crystal structure of iron is detected through Zeiss metallographic microscope. Figures 19(a)-19(c) are the steel cooled in laminar cooling process with just the CT controlled, while Figures 19(e) and 19(f) show that the temperature control is in line with the designed curve. $(a, d)$ is the surface impurity detection. (b, e) is at the thickness of $1 / 4$, while $(c, f)$ is at the $1 / 2$ thickness. The comparison between the two groups of metallographic pictures shows that the TC control makes fewer impurities and avoids the widmanstatten and a large crystal structure harmful to mechanical property.

\section{Conclusion}

In this study, a novelty modeling method and GPC-PID control strategy are presented to control the temperature curve in laminar cooling process. First, the cooling mechanism in laminar cooling process is investigated; then the TS fuzzy model 

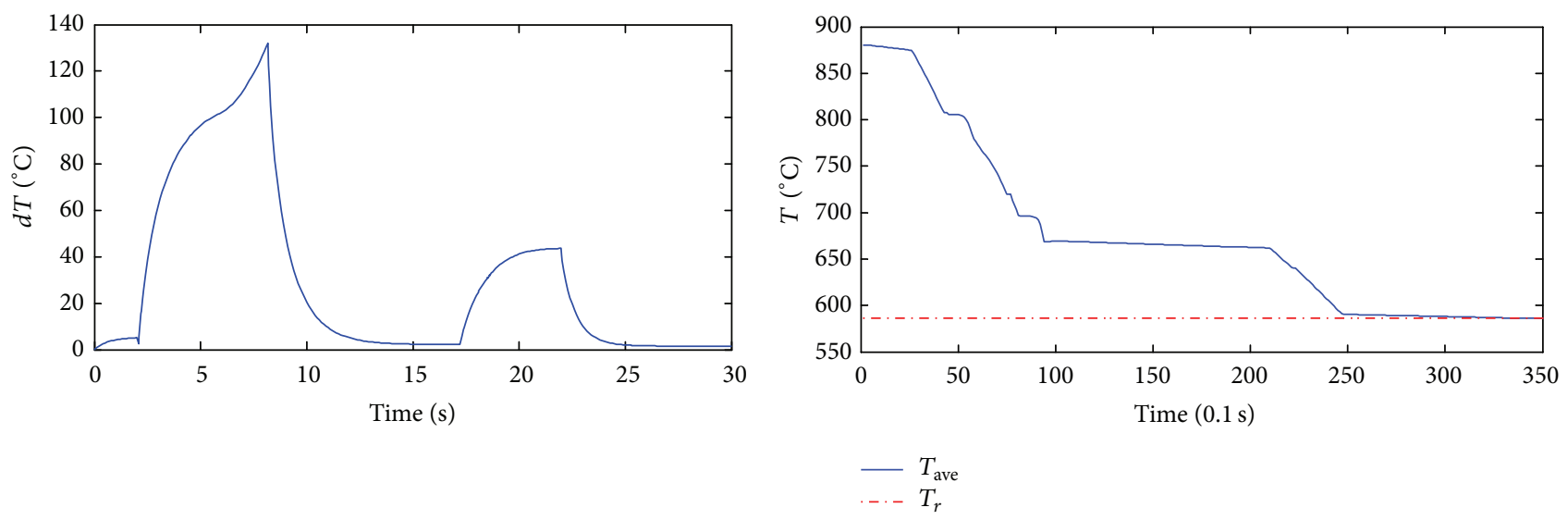

(a)
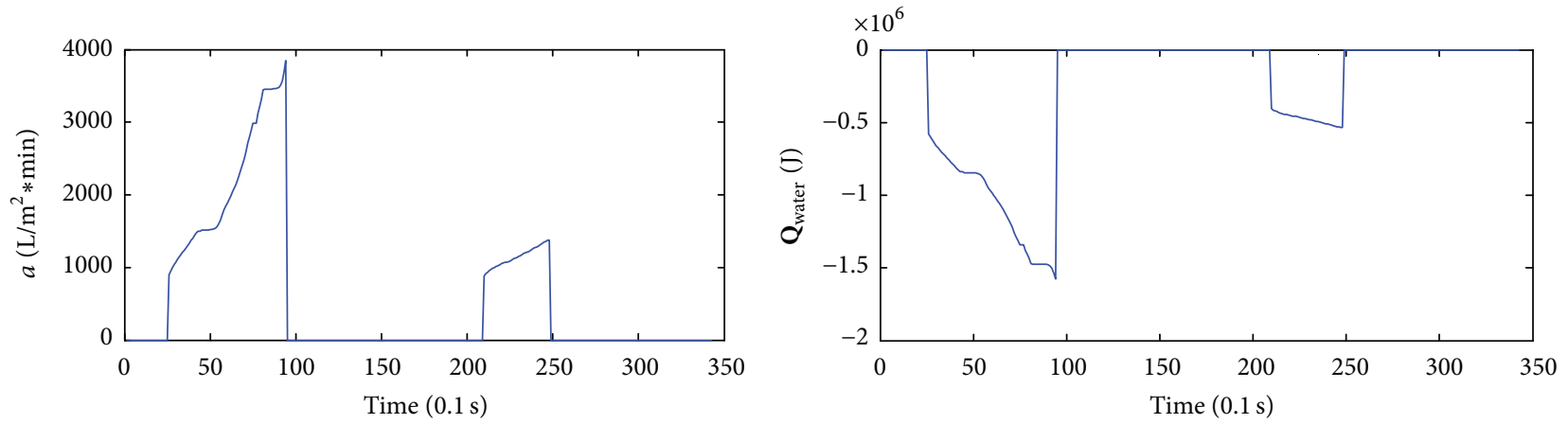

— Water.signals.values

(c)

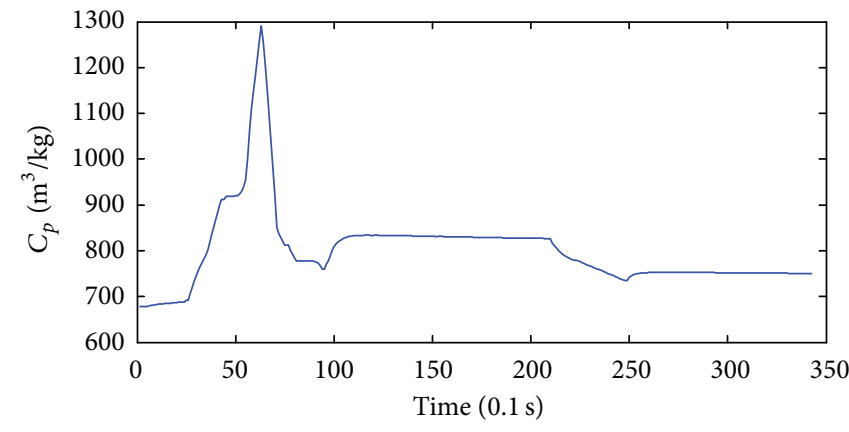

(e) (d)

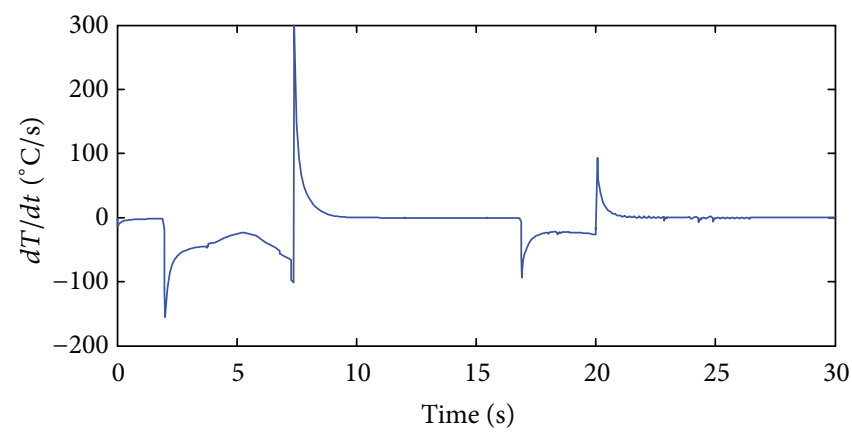

(f)

Figure 14: The parameters calculated by the model.

which boasts high self-study ability by combining data filtering method and parameter recognizing method is introduced into the intelligent model. The new modeling method proposed by this paper enables the intelligent laminar flow cooling model to monitor the process of a laminar flow cooling process rapidly. Second, several subgoals based on the location of the runout table are set to make the temperature curve be realized with a few computational burdens. In order to guarantee the steel plate cooling along the target temperature curve, the GPC-PID control method is implemented, which makes the distributed PID controllers achieve the subgoals. Third, the dSPACE control board which is running the intelligent model is provided to make the GPC-PID applied in the control system without large-scale reconstruction. Finally, the data collected from the real production line demonstrates the efficiency and precision of the control strategy formulated in this paper, and the metallography detection by the metallographic microscope indicates that applying the temperature curve control can obtain finer microstructure compared with the CT control.

Although a practical modeling and an effective control strategy have been proposed to obtain an ideal result successfully, there are still some improvements to be accomplished further about this work. First, the number of the subgoals cannot be added more than 6 due to the complexity of the control method and the constraint of the calculative ability of 


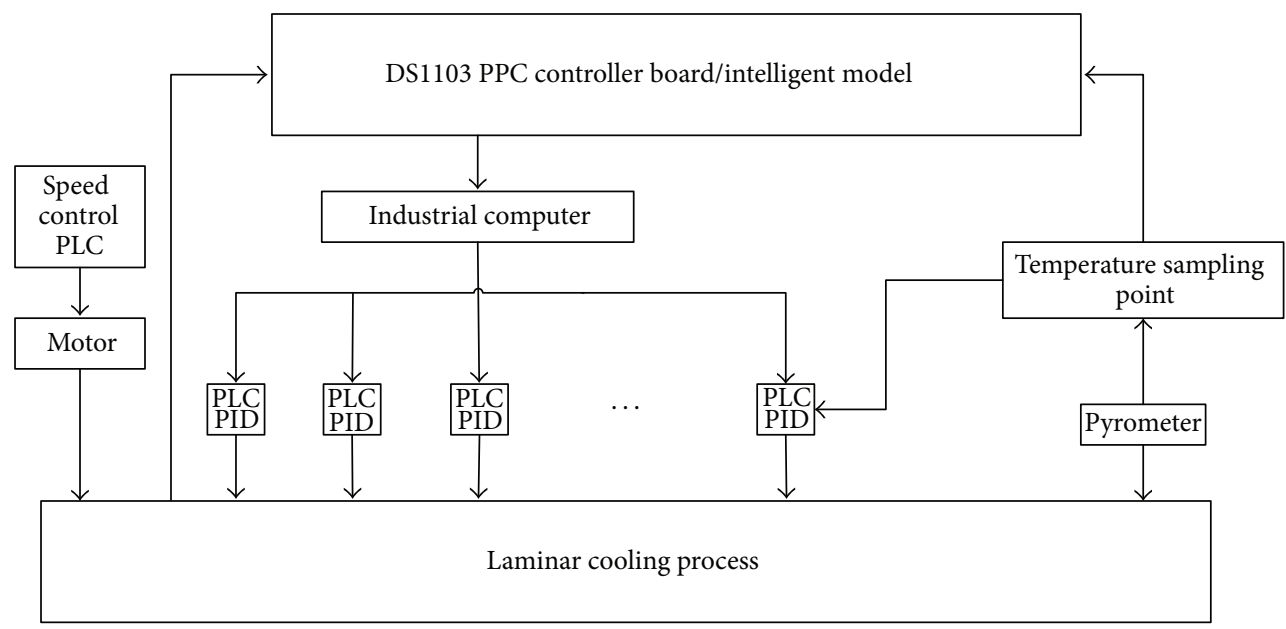

FIGURE 15: The structure of the control system after reorganizing.

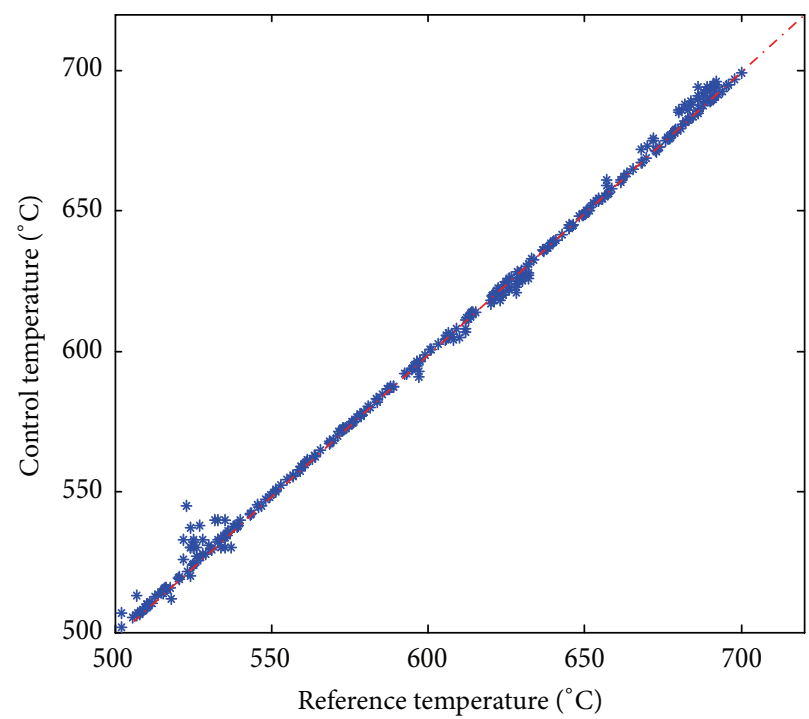

FIGURE 16: The industrial CT data using the present control method.

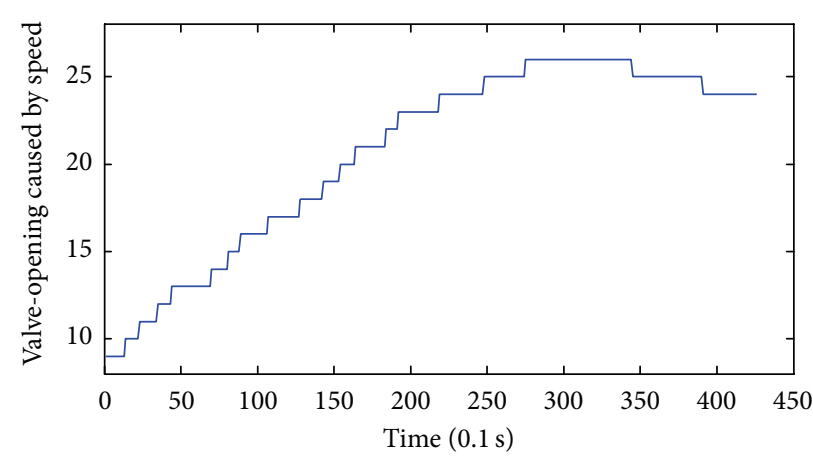

(a)

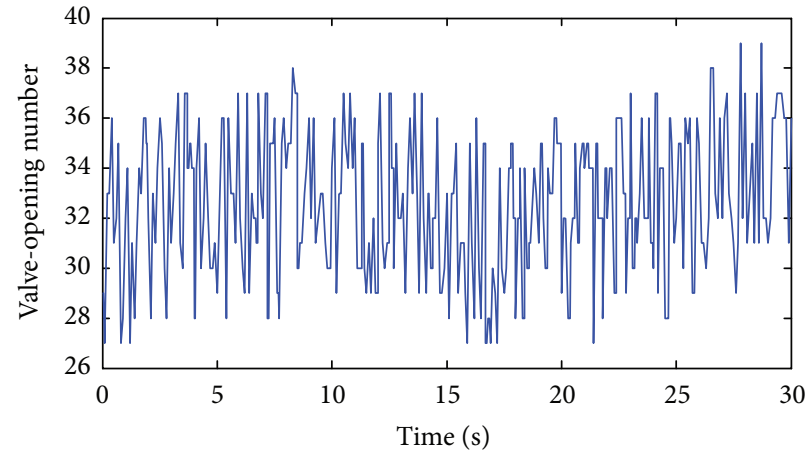

(b)

FIgURE 17: The control variables in the cooling process. 


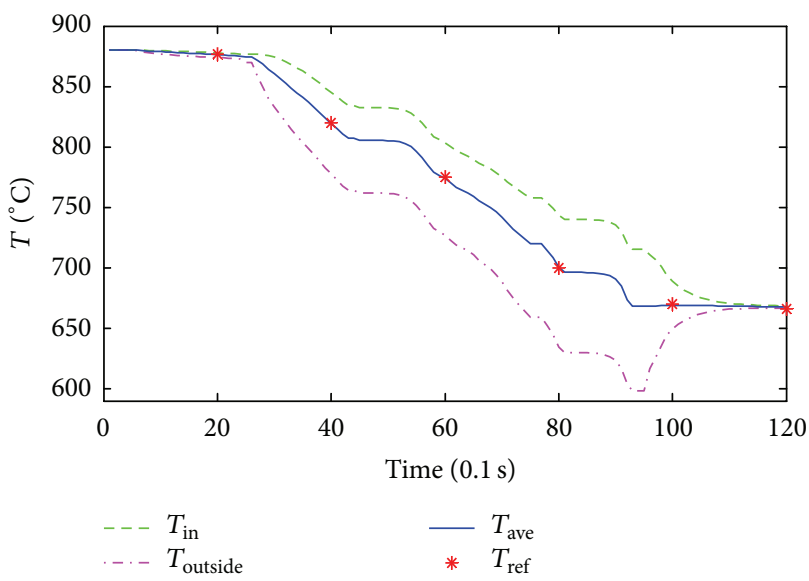

(a)

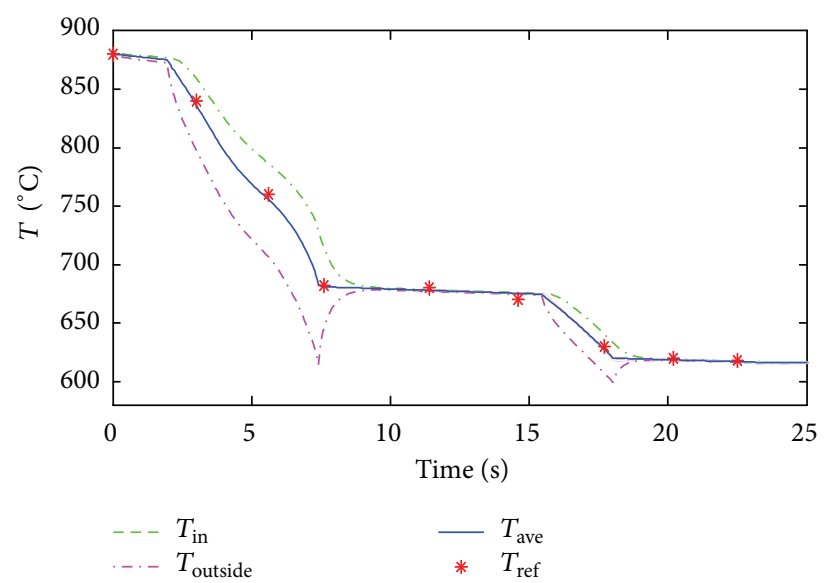

(b)

FIGURE 18: The temperature curve dropping along the subgoals.

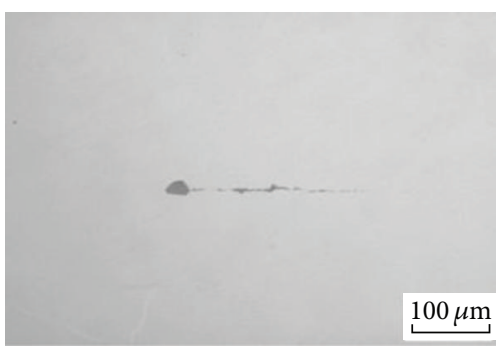

(a)

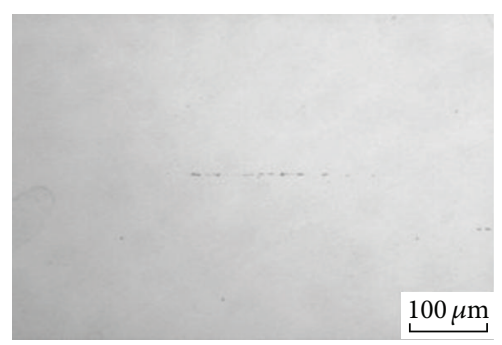

(d)

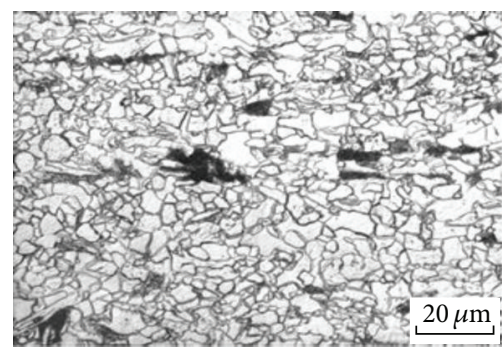

(b)

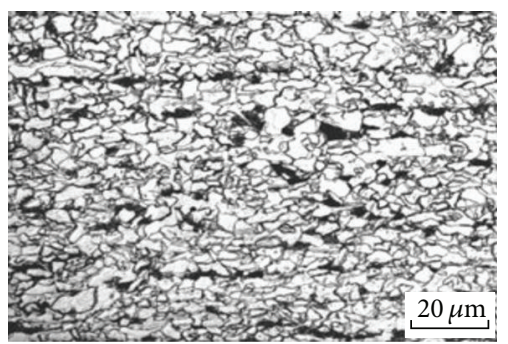

(e)

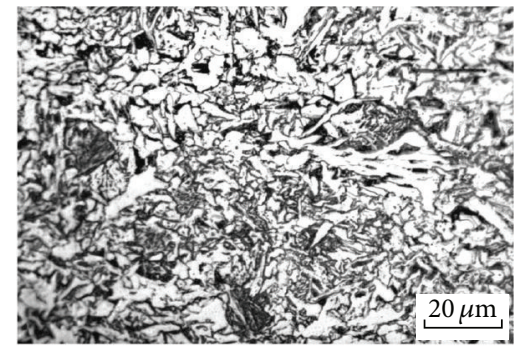

(c)

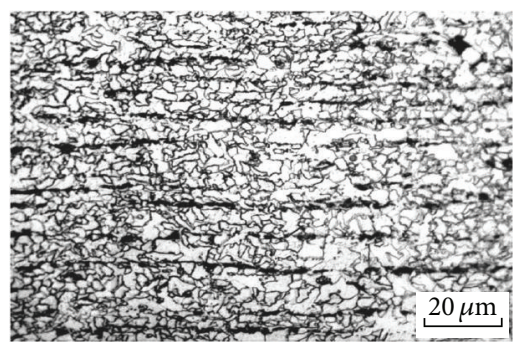

(f)

FIGURE 19: The metallography detection of two sets of steel.

industrial computers. Second, the local CARIMA models need to be adjusted after some steel plate production. Those problems will be solved in future works.

\section{Conflict of Interests}

The authors declare that there is no conflict of interests regarding the publication of this paper.

\section{References}

[1] S. Sikdar and A. Mukhopadhyay, "Numerical determination of heat transfer coefficient for boiling phenomenon at runout table of hot strip mill," Ironmaking and Steelmaking, vol. 31, no. 6, pp. 495-502, 2004.
[2] S. Serajzadeh, "Prediction of temperature distribution and phase transformation on the run-out table in the process of hot strip rolling," Applied Mathematical Modelling, vol. 27, no. 11, pp. 861-875, 2003.

[3] Y. Zheng, S. Li, and X. Wang, "An approach to model building for accelerated cooling process using instance-based learning," Expert Systems with Applications, vol. 37, no. 7, pp. 5364-5371, 2010.

[4] H.-B. Xie, X.-H. Liu, G.-D. Wang, and Z.-P. Zhang, "Optimization and model of laminar cooling control system for hot strip mills," Journal of Iron and Steel Research International, vol. 13, no. 1, pp. 18-22, 2006.

[5] S. P. Guan, H.-X. Li, and S. K. Tso, "Multivariable fuzzy supervisory control for the laminar cooling process of hot rolled slab," IEEE Transactions on Control Systems Technology, vol. 9, no. 2, pp. 348-356, 2001. 
[6] G. van Ditzhuijzen, "The controlled cooling of hot rolled strip: a combination of physical modeling, control problems and practical adaption," IEEE Transactions on Automatic Control, vol. 38, no. 7, pp. 1060-1065, 1993.

[7] D. M. Lee and S. G. Choi, "Application of on-line adaptable neural network for the rolling force set-up of a plate mill," Engineering Applications of Artificial Intelligence, vol. 17, no. 5, pp. 557-565, 2004.

[8] H.-X. Li and S. P. Guan, "Hybrid intelligent control strategy: supervising a DCS-controlled batch process," IEEE Control Systems Magazine, vol. 21, no. 3, pp. 36-46, 2001.

[9] E.-Y. Liu, D.-H. Zhang, J. Sun, L.-G. Peng, B.-H. Gao, and L.$\mathrm{T}$. Su, "Algorithm design and application of laminar cooling feedback control in hot strip mill," Journal of Iron and Steel Research, International, vol. 19, no. 4, pp. 39-42, 2012.

[10] Y. Zheng, S. Y. Li, and X. Wang, "An approach to model building for accelerated cooling process using instance-based learning," Expert Systems with Applications, vol. 37, no. 7, pp. 5364-5371, 2010.

[11] J. Wang, G.-D. Wang, and X.-H. Liu, "Hot strip laminar cooling control model," Journal of Iron and Steel Research International, vol. 11, no. 5, pp. 13-17, 2004.

[12] B. Han, Z. P. Zhang, X. H. Liu, and G. D. Wang, "Element tracking strategies for hot striplaminar cooling control," Journal of Iron and Steel Research International, vol. 12, no. 3, pp. 18-21, 27, 2005.

[13] H. B. Xie, Z. Y. Jiang, X. H. Liu et al., "Application of fuzzy control of laminar cooling for hot rolled strip," Journal of Materials Processing Technology, vol. 187-188, pp. 715-719, 2007.

[14] D. Y. Gong, J. Z. Xu, L. G. Peng, G. D. Wang, and X. H. Liu, "Selflearning and its application to laminar cooling, model of hot rolled strip," Journal of Iron and Steel Research International, vol. 14, no. 4, pp. 11-14, 2007.

[15] H. N. Han, J. K. Lee, H. J. Kim, and Y.-S. Jin, "A model for deformation, temperature and phase transformation behavior of steels on run-out table in hot strip mill," Journal of Materials Processing Technology, vol. 128, no. 1-3, pp. 216-225, 2002.

[16] Y. Zheng, N. Li, and S. Y. Li, "Hot-rolled strip laminar cooling process plant-wide temperature monitoring and control," Control Engineering Practice, vol. 21, no. 1, pp. 23-30, 2013.

[17] H.-X. Li and S. Guan, "Hybrid intelligent control strategy. Supervising a DCS-controlled batch process," IEEE Control Systems, vol. 21, no. 3, pp. 36-48, 2001.

[18] M. Tan, S. Li, J. Pian, and T. Chai, "Case-based modeling of the laminar cooling process in a hot rolling mill," in Intelligent Control and Automation, D.-S. Huang, K. Li, and G. W. Irwin, Eds., vol. 344 of Lecture Notes in Control and Information Sciences, pp. 264-274, Springer, 2006.

[19] Y. Zheng, S. Li, and X. Wang, "Distributed model predictive control for plant-wide hot-rolled strip laminar cooling process," Journal of Process Control, vol. 19, no. 9, pp. 1427-1437, 2009.

[20] T. Takagi and M. Sugeno, "Fuzzy identification of systems and its applications to modeling and control," IEEE Transactions on Systems, Man and Cybernetics, vol. 15, no. 1, pp. 116-132, 1985.

[21] P. P. Angelov and D. P. Filev, "An approach to online identification of Takagi-Sugeno fuzzy models," IEEE Transactions on Systems, Man, and Cybernetics, Part B: Cybernetics, vol. 34, no. 1, pp. 484-498, 2004.

[22] H. J. Lee and D. W. Kim, "Robust stabilization of T-S fuzzy systems: fuzzy static output feedback under parametric uncertainty," International Journal of Control, Automation and Systems, vol. 7, no. 5, pp. 731-736, 2009.
[23] D. W. Clarke, C. Mohtadi, and P. S. Tuffs, "Generalized predictive control. Part I. The basic algorithm," Automatica, vol. 23, no. 2, pp. 137-148, 1987.

[24] T. Sato, "Design of a GPC-based PID controller for controlling a weigh feeder," Control Engineering Practice, vol. 18, no. 2, pp. 105-113, 2010.

[25] T. Sato, A. Inoue, and T. Yamamoto, "Improvement of tracking performance in designing a GPC based PID controller using a time-varying proportional gain," IEEJ Transactions on Electrical and Electronic Engineering, vol. 1, no. 4, pp. 438-441, 2006. 


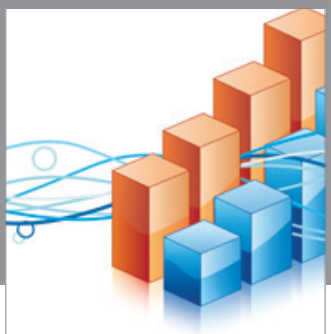

Advances in

Operations Research

vatem alat4

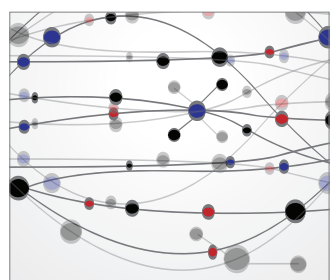

\section{The Scientific} World Journal
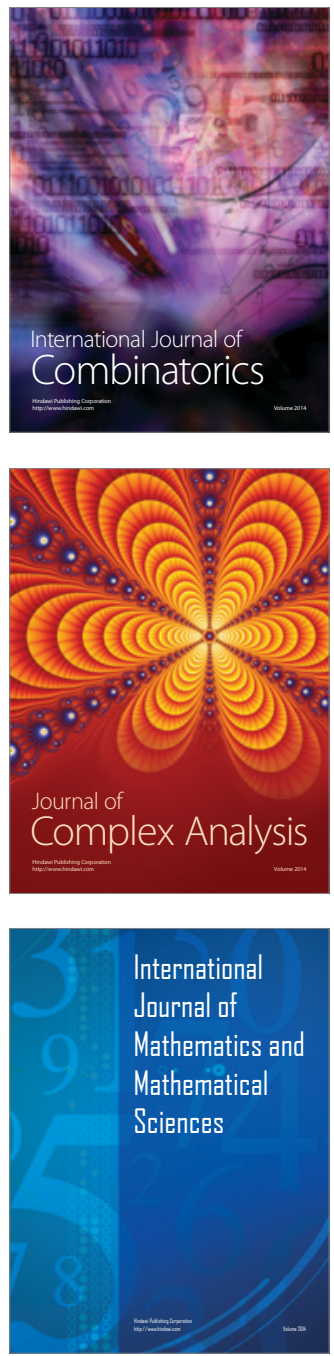
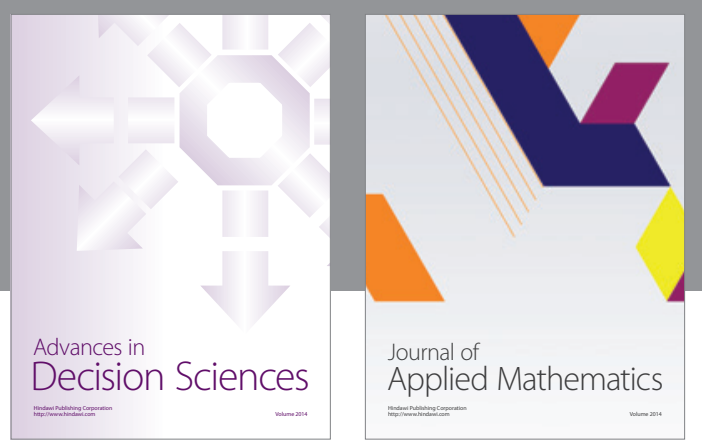

Algebra

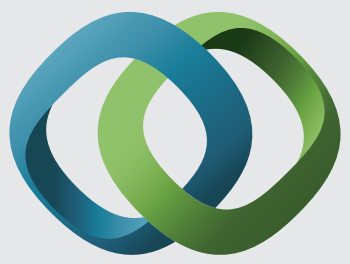

\section{Hindawi}

Submit your manuscripts at

http://www.hindawi.com
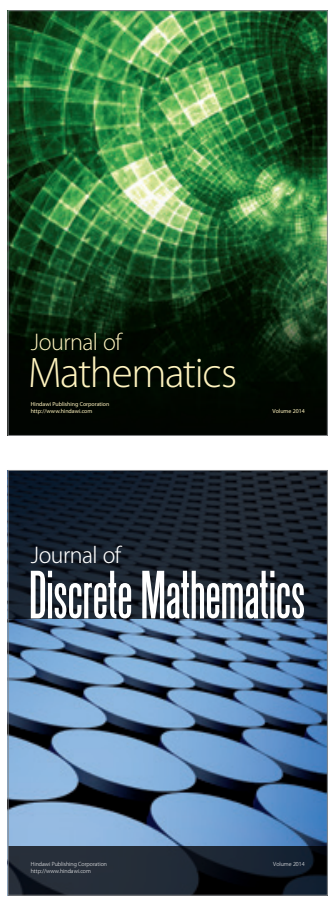

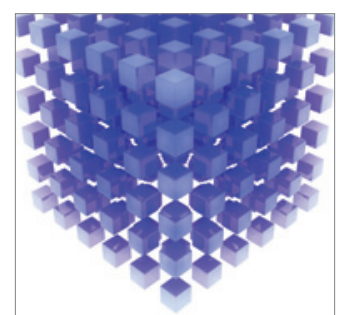

Mathematical Problems in Engineering
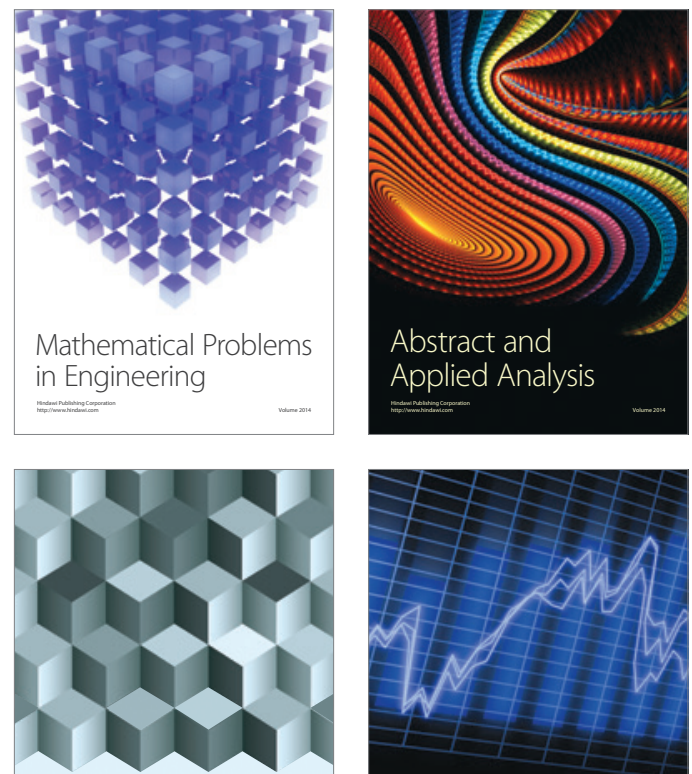

Journal of

Function Spaces

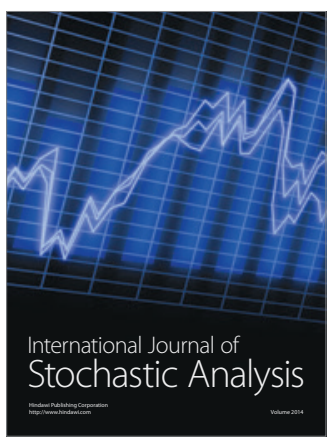

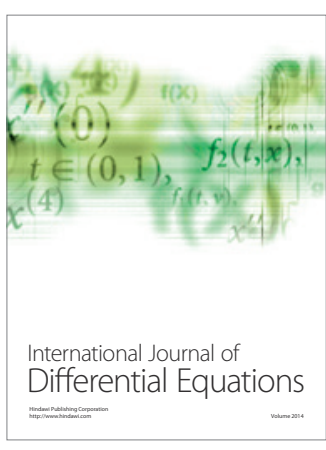
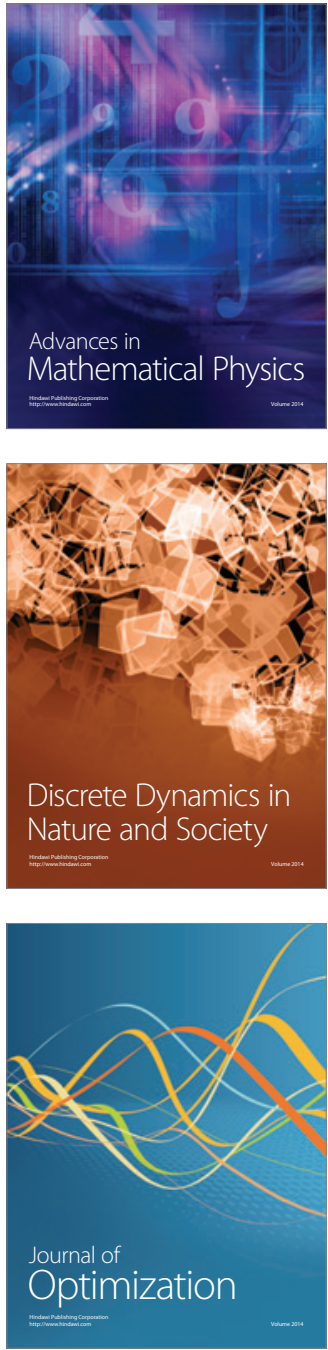